University of Wollongong

Research Online

Faculty of Engineering and Information

Faculty of Engineering and Information

Sciences - Papers: Part B

Sciences

2019

\title{
Effect of water-based nanolubricant containing nano-TiO2 on friction and wear behaviour of chrome steel at ambient and elevated temperatures
}

Hui Wu

University of Wollongong, hwu@uow.edu.au

Fanghui Jia

University of Wollongong, fj910@uowmail.edu.au

Jingwei Zhao

University of Wollongong, jzhao@uow.edu.au

Shuiquan Huang

University of Queensland

Lianzhou Wang

University of Queensland, I.wang@uq.edu.au

See next page for additional authors

Follow this and additional works at: https://ro.uow.edu.au/eispapers1

Part of the Engineering Commons, and the Science and Technology Studies Commons

Research Online is the open access institutional repository for the University of Wollongong. For further information contact the UOW Library: research-pubs@uow.edu.au 


\title{
Effect of water-based nanolubricant containing nano-TiO2 on friction and wear behaviour of chrome steel at ambient and elevated temperatures
}

\begin{abstract}
A novel experimental method was developed through a ball-on-disk tribometer to study the friction and wear behaviour of a chrome steel at temperatures of 25,200 and $500^{\circ} \mathrm{C}$. Water-based nanolubricants containing different concentrations of nano-TiO2 from 0.4 to $8.0 \mathrm{wt} \%$ were used to investigate their effects on friction-reduction and anti-wear mechanisms, in comparison to the benchmarks under dry and water conditions. The results show that the water-based nanolubricants can significantly reduce coefficient of friction (COF) and improve wear resistance of the chrome steel at both ambient and elevated temperatures. In particular, the use of nanolubricant containing an optimal concentration (4.0 wt\%) of nano-TiO2 leads to the lowest COF and the smallest ball wear among all the lubrication conditions. The friction-reduction and anti-wear mechanisms are ascribed to the rolling \& polishing effects, semisolid film and solid layer contributed by the nano-TiO2 at temperatures of 25,200 and $500{ }^{\circ} \mathrm{C}$, respectively.
\end{abstract}

\section{Keywords}

wear, friction, nano-tio2, containing, temperatures, nanolubricant, elevated, water-based, effect, ambient, steel, chrome, behaviour

\section{Disciplines \\ Engineering | Science and Technology Studies}

\section{Publication Details}

Wu, H., Jia, F., Zhao, J., Huang, S., Wang, L., Jiao, S., Huang, H. \& Jiang, Z. (2019). Effect of water-based nanolubricant containing nano-TiO2 on friction and wear behaviour of chrome steel at ambient and elevated temperatures. Wear, 426-427 (Part A), 792-804.

\section{Authors}

Hui Wu, Fanghui Jia, Jingwei Zhao, Shuiquan Huang, Lianzhou Wang, Sihai Jiao, Han Huang, and Zhengyi Jiang 


\section{Effect of water-based nanolubricant containing nano- $\mathrm{TiO}_{2}$ on friction and wear behaviour of chrome steel at ambient and elevated temperatures}

Hui $\mathrm{Wu}^{\mathrm{a}}$, Fanghui Jia ${ }^{\mathrm{a}}$, Jingwei Zhao ${ }^{\mathrm{a}}$, Shuiquan Huang ${ }^{\mathrm{b}}$, Lianzhou Wang ${ }^{\mathrm{c}}$, Sihai Jiao ${ }^{\mathrm{d}}$, Han Huang ${ }^{\mathrm{b} *}$, Zhengyi Jiang ${ }^{a^{*}}$

a School of Mechanical, Materials, Mechatronic and Biomedical Engineering, University of Wollongong, Wollongong, NSW 2522, Australia

b School of Mechanical and Mining Engineering, The University of Queensland, Brisbane, QLD 4072, Australia

${ }^{c}$ School of Chemical Engineering, The University of Queensland, Brisbane, QLD 4072, Australia

${ }^{\mathrm{d}}$ Baosteel Research Institute (R\&D Centre), Baoshan Iron \& Steel Co., Ltd., Shanghai 200431, China

Abstract: A novel experimental method was developed through a ball-on-disk tribometer to study the friction and wear behaviour of a chrome steel at temperatures of 25,200 and $500{ }^{\circ} \mathrm{C}$. Water-based nanolubricants containing different concentrations of nano- $\mathrm{TiO}_{2}$ from 0.4 to $8.0 \mathrm{wt} \%$ were used to investigate their effects on friction-reduction and anti-wear mechanisms, in comparison to the benchmarks under dry and water conditions. The results show that the water-based nanolubricants can significantly reduce coefficient of friction (COF) and improve wear resistance of the chrome steel at both ambient and elevated temperatures. In particular, the use of nanolubricant containing an optimal concentration (4.0 wt $\%)$ of nano- $\mathrm{TiO}_{2}$ leads to the lowest $\mathrm{COF}$ and the smallest ball wear among all the lubrication conditions. The friction-reduction and anti-wear mechanisms are ascribed to the rolling \& polishing effects, semisolid film and solid layer contributed by the nano- $\mathrm{TiO}_{2}$ at temperatures of 25,200 and $500{ }^{\circ} \mathrm{C}$, respectively.

Keywords: Nano- $\mathrm{TiO}_{2}$; Water-based nanolubricant; Coefficient of friction; Elevated temperature

*Corresponding authors.

E-mail addresses: han.huang@uq.edu.au (H. Huang),jiang@uow.edu.au (Z. Jiang) 


\section{Introduction}

Energy saving and environmental protection are being subjected to considerable concern in modern times [1]. Recently, great efforts have been made to minimise energy loss and environmental pollution in engineering applications [2-5]. Lubrication technology is one of the most useful approaches to solve these issues as the primary causes of energy loss in engineering fields are friction and wear [6]. It is welldocumented that the conventional lubricating system including base oils such as mineral oil [7], synthetic oil [8] and biological oil [9], oil-in-water emulsions [10,11] and other oil-based lubricants [12-14] can decrease friction and wear to a certain extent. The application and discharge of oil, however, inevitably trigger environmental issues due to its nonbiodegradable nature and inherent toxicity [7]. In this regard, developing environment-friendly water-based lubricants with excellent tribological performance is increasingly important and urgently needed. Considering the insufficient film thickness of water due to its low viscosity and chemical reaction with metals [3], many researchers have focused on using nanomaterials as nanoadditives dispersed in water in order to enhance the lubricating property of water. These nanoadditives include metals [15, 16], metallic oxides [17-25], non-metallic oxides [26, 27], metal sulphides [28-30], composites [31, 32], fullerene [33,34] and other carbon materials [35-43]. For examples, Zhang et al. [16] prepared water-based nanolubricant by adding surface-capped nano-Cu into distilled water

for four-ball test. They found that the nano-Cu with an average diameter of $2 \mathrm{~nm}$ could be uniformly dispersed in distilled water without apparent agglomeration. The improved tribological properties of distilled water were ascribed to the formation of boundary lubrication film produced by tribo-chemical reaction between the nano- $\mathrm{Cu}$ and sliding steels. Radice and Mischler [17] prepared water-based nanolubricants by adding $10 \mathrm{vol} \%$ nano- $\mathrm{Al}_{2} \mathrm{O}_{3}$ into deionised water with an acetate buffer solution. The reciprocating wear testing results showed that the lubricant containing nano- $\mathrm{Al}_{2} \mathrm{O}_{3}$ decreased COF by 40 $50 \%$, compared to that without nanoparticles (NPs) due to a third body formed by NPs trapped within the contact area. Bao et al. [27] added surface modified nano- $\mathrm{SiO}_{2}$ into water to prepare well-dispersed waterbased lubricants. The tribological properties evaluated by four-ball and pin-on-disk tests demonstrated that the lubricant containing $0.3 \mathrm{wt} \%$ nano- $\mathrm{SiO}_{2}$ caused the best load-carrying and anti-wear performance due to the miniature ball bearing effect and the self-repairing ability of $\mathrm{SiO}_{2} \mathrm{NPs}$ between the friction pairs. Meng et al. [30] prepared water-dispersible $\mathrm{MoS}_{2}$ NPs, and investigated tribological behaviour of the synthetic nano- $\mathrm{MoS}_{2}$ dispersed in distilled water using a four-ball tester. The results indicated that nano$\mathrm{MoS}_{2}$ can effectively improve the friction-reduction, anti-wear and load-carrying abilities of distilled water, showing a promising potential as a nanoadditive in water-based lubricant. Zhang et al. [31] synthesised $\mathrm{Cu} / \mathrm{SiO}_{2}$ nanocomposite by use of a sol-gel method, and studied its tribological properties when added into distilled water via a four-ball tester. The results showed that the water-based lubricant containing nano- 
$\mathrm{Cu} / \mathrm{SiO}_{2}$ was able to significantly reduce the friction and wear of steel friction pairs, compared to distilled water. This was ascribed to the formation of a protective film composed of $\mathrm{Cu}$ and $\mathrm{SiO}_{2}$. Liang et al. [38] prepared aqueous graphene solution with the assistance of a non-ionic surfactant i.e. Triton X-100. The results obtained from ball-on-disk tribological tests showed that a small amount addition of graphene enabled a substantial reduction of COF by $81.3 \%$ and also the wear volume by two orders of magnitude in comparison with deionised water. In particular, research efforts have been directed towards using $\mathrm{TiO}_{2} \mathrm{NPs}$ as additives that can be dispersed uniformly in water, showing promising and inspiring lubrication performance [18, 23-25].

The previous studies regarding tribological properties of water-based nanolubricants, however, were mainly conducted at the ambient temperature. The evaluation of tribological properties using water-based nanolubricants at elevated temperatures has rarely been performed or reported until now. In our previous studies [23, 24], the lubrication mechanisms of water-based nanolubricant containing $\mathrm{TiO}_{2} \mathrm{NPs}$ were systematically investigated via ball-on-disk tests at ambient temperature by varying surface conditions (surface roughness and oxidation) of applied disk and concentrations of nano- $\mathrm{TiO}_{2}$ dispersed in water. The objective of this study is to reveal the effects of temperature and nano- $\mathrm{TiO}_{2}$ concentration on friction and wear behaviour of a chrome steel (roll material) with water-based nanolubricant, using an innovative ballon-disk configuration. This study will provide a reliable and effective way to evaluate the roll service life in hot steel rolling when using water-based nanolubricant.

\section{Experimental details}

\subsection{Materials}

An E52100 chrome steel ball and a mild steel (MS) disk were used as the friction pair in a ball-on-disk tribometer, in which the ball represented the roll material while the disk represented the strip steel. The chemical compositions of the two materials are listed in Table 1. All the balls being used had a diameter of $9.5 \mathrm{~mm}$ and a surface roughness of $0.02 \mu \mathrm{m}$ in $\mathrm{R}_{\mathrm{a}}$. The disks were machined to a dimension of $\varnothing 40 \mathrm{~mm} \times$ $8 \mathrm{~mm}$ with a surface roughness of $0.11 \mu \mathrm{m}$ in $\mathrm{R}_{\mathrm{a}}$. The hardnesses of the ball and disk materials are approximately 780 and $90 \mathrm{HV}$, respectively. Surface morphologies and 3D profiles of the friction pair are shown in Fig. 1. It can be seen that the ball surface is quite smooth, while the disk has significant scratches on its surface. This rough surface was designed to differentiate the relevantly smooth one based on the previous study [24].

Table 1 Chemical compositions of the ball and disk materials (wt \%).

\begin{tabular}{ccccccccc}
\hline Materials & $\mathrm{C}$ & $\mathrm{Si}$ & $\mathrm{Mn}$ & $\mathrm{Cr}$ & $\mathrm{Cu}$ & $\mathrm{Mo}$ & $\mathrm{Nb}+\mathrm{V}+\mathrm{Ti}$ & $\mathrm{P}+\mathrm{S}$ \\
\hline Ball-E52100 & 1.0 & 0.25 & 0.35 & 1.5 & 0.30 & 0.10 & - & $\leq 0.03$ \\
Disk-MS & 0.05 & 0.02 & 0.25 & 0.01 & - & - & $<0.01$ & $\leq 0.03$ \\
\hline
\end{tabular}


(a)

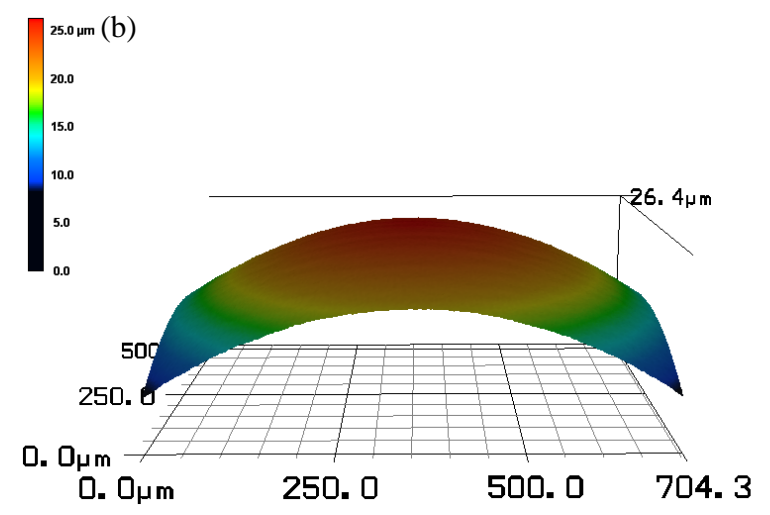

50um
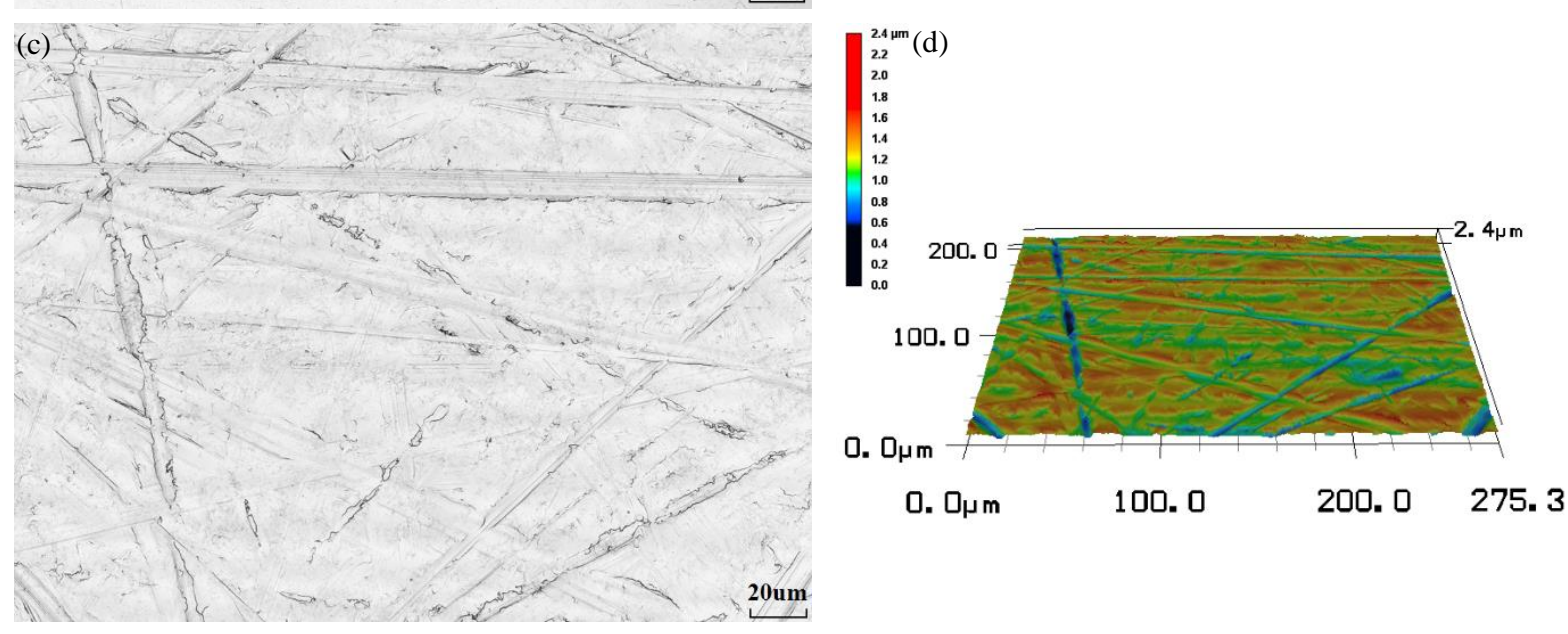

Fig. 1 Surface morphologies and 3D profiles of (a, b) Cr steel ball, and (c, d) mild steel disk.

The water-based nanolubricants being used in the test consist of $\mathrm{TiO}_{2} \mathrm{NPs}$, polyethyleneimine (PEI), glycerol and balanced water. The nano- $\mathrm{TiO}_{2}$ is $\mathrm{P} 25$, a mixture of $75 \%$ of anatase and $25 \%$ of rutile with around $20 \mathrm{~nm}$ in diameter. It is worth noticing that the reason of choosing P25 as the nanoadditive in water is due to its much lower cost than those of pure anatase and rutile.

The synthesis procedure of nanolubricants can be found elsewhere, showing excellent dispersibility and stability [4, 24]. The chemical compositions of the nanolubricants being used in this study are shown in Table 2. For comparison, testing conditions without lubrication (i.e. dry condition) and with pure water lubrication were also used. 
Table 2 Chemical compositions of employed lubricants.

\begin{tabular}{cc}
\hline Lubrication type & Description \\
\hline 1 & Dry \\
2 & Water \\
3 & $0.4 \mathrm{wt} \% \mathrm{TiO}_{2}+0.004 \mathrm{wt} \% \mathrm{PEI}+10.0 \mathrm{vol} \%$ glycerol + balance water \\
4 & $1.0 \mathrm{wt} \% \mathrm{TiO}_{2}+0.01 \mathrm{wt} \% \mathrm{PEI}+10.0 \mathrm{vol} \%$ glycerol + balance water \\
5 & $2.0 \mathrm{wt} \% \mathrm{TiO}_{2}+0.02 \mathrm{wt} \% \mathrm{PEI}+10.0 \mathrm{vol} \%$ glycerol + balance water \\
6 & $4.0 \mathrm{wt} \% \mathrm{TiO}_{2}+0.04 \mathrm{wt} \% \mathrm{PEI}+10.0$ vol $\%$ glycerol + balance water \\
7 & $8.0 \mathrm{wt} \% \mathrm{TiO}_{2}+0.08 \mathrm{wt} \% \mathrm{PEI}+10.0 \mathrm{vol} \%$ glycerol + balance water \\
\hline
\end{tabular}

\subsection{Tribological tests}

An Rtec MFT-5000 Muti-functional Tribometer was used to measure the coefficients of friction (COF) under the ball-on-disk testing protocols. The configuration of this tribometer for the tests at ambient temperature was the same to that reported in our previous study [23], in which the disk surface was covered by a layer of lubricant with a fixed volume of $2 \mathrm{ml}$ prior to each tribological test under liquid lubrication. In this way, the initial conditions of the tribological tests can be well controlled. In contrast, the configuration was restructured with an innovative model to continuously supply the droplets of lubricants during sliding process, as shown in Fig. 2. It can be seen that the lubricants were contained in an infusion bag, and flowed along a plastic pipe that was connected to a copper pipe, and then dropped consecutively onto a rotating pre-heated disk. The copper pipe was bound with a ball holder to resist a high temperature close to the hot disk. The temperature of the disk can be well controlled by the induction heater ahead of each tribological test, and the flowing rate of the lubricants can be adjusted by a flow regulator equipped.

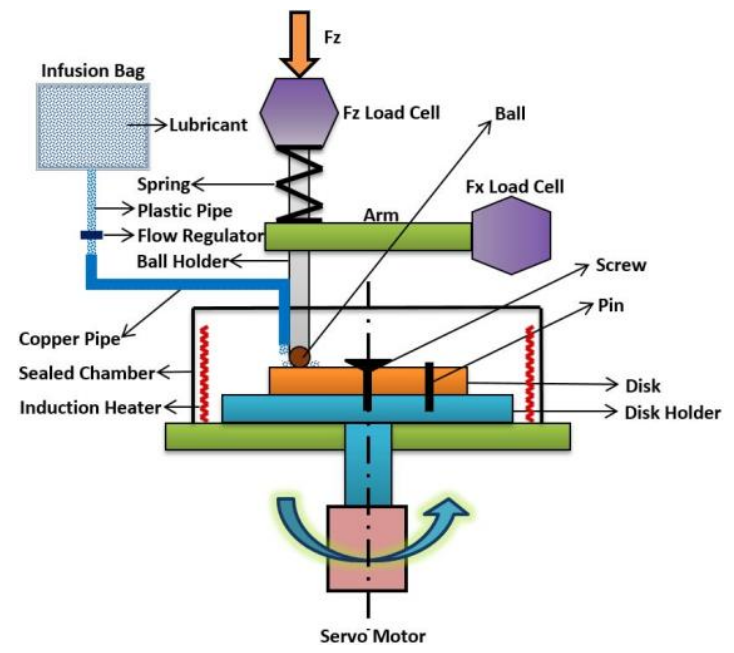

Fig. 2 Schematic of the ball-on-disk tribometer used for tribological tests at elevated temperatures. 
The tribological testing conditions at ambient and elevated temperatures are shown in Table 3. A constant load of $50 \mathrm{~N}$ was applied to press the $\mathrm{Cr}$ steel ball against the rotating MS disk for a period of 5 minutes. The reason of choosing a relatively short sliding time was to decrease the stacking of nanolubricants caused by continuous droplets, which might impede movement of the ball. The linear speed and the radius of the wear track were $50 \mathrm{~mm} / \mathrm{s}$ and $14 \mathrm{~mm}$, respectively. It should be noted that a relatively low sliding speed of $50 \mathrm{~mm} / \mathrm{s}$ was adopted for the minimisation of hydrodynamic effect. During testing, the time histories of COF were recorded. When a test was completed, both the ball and the disk were disassembled from the tribometer and then cleaned ultrasonically in an ethanol bath for 5 minutes to remove any loose debris and surplus lubricants. For each condition, the same test was repeated for three times.

Table 3 Tribological testing conditions at ambient and elevated temperatures.

\begin{tabular}{ccccc}
\hline Normal load$/ \mathrm{N}$ & Speed $/ \mathrm{mm} \cdot \mathrm{s}^{-1}$ & Time $/ \mathrm{min}$ & Temperature $/{ }^{\circ} \mathrm{C}$ & Radius of wear track $/ \mathrm{mm}$ \\
\hline 50 & 50 & 5 & 25,200 and 500 & 14 \\
\hline
\end{tabular}

\subsection{Characterisation techniques}

Wear scars of the balls produced after tribological tests were observed under a KEYENCE VK-X100K 3D Laser Scanning Microscope. Surface morphologies and 3D profiles of the worn zones were examined. Wear tracks of the disks were further examined using a JEOL model JSM-7001F Scanning Electron Microscope (SEM) equipped with an Energy Dispersive Spectrometer (EDS).

\section{Results}

\subsection{Ball-on-disk tests at ambient temperature}

Fig. 3 shows the COF curves and values measured at ambient temperature under different lubrication conditions. Fig. 3(a) shows that the COF curve caused by dry condition presents large fluctuation in the running-in period, and gradually drops to a stable level for the rest of the sliding. When using water lubrication, the $\mathrm{COF}$ is reduced to a lower and more stable level after a minor fluctuation in the first 10 seconds. The use of water-based nanolubricants further decreases the COF to a much lower level, even though there is also a slight fluctuation in the first 15 seconds. The COF values obtained at the stable stage of sliding are averaged from the three-time repeated tests, as shown in Fig. 3(b). It is found that the averaged COF value is significantly reduced from the dry and pure water lubrication of around 0.45 when the nanolubricants are applied. The increase of nano- $\mathrm{TiO}_{2}$ concentration in water only slightly reduces the COF with the lowest value of 0.273 achieved when $4.0 \mathrm{wt} \% \mathrm{TiO}_{2}$ is used. A further increase of nano- $\mathrm{TiO}_{2}$ concentration to $8.0 \mathrm{wt} \%$, however, results in a slightly higher COF value. Therefore, a concentration of 
$4.0 \mathrm{wt} \%$ appears to be the optimal one in the water-based nanolubricants, which enables the reduction of COF by around $40 \%$ from that under the dry condition.
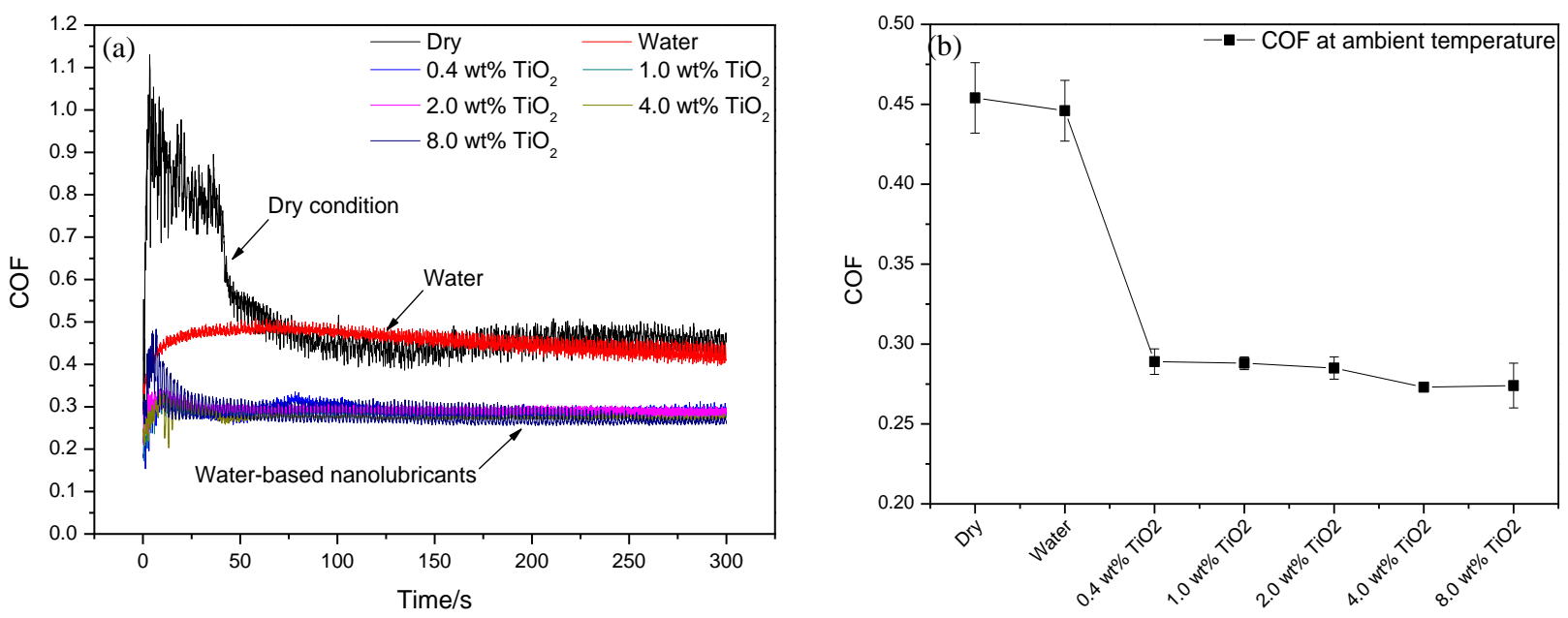

Fig. 3 (a) COF curves as functions of sliding time, and (b) averaged COF values at the stable sliding stage for all the testing conditions at ambient temperature.

Fig. 4 shows the surface morphologies of the worn balls obtained at ambient temperature under different lubrication conditions. It is observed from Fig. 4(a) and (b) that both dry condition and pure water produce relatively large wear scars with significant scratches, in comparison to those generated by nanolubricants. The brown substances (arrow) on the ball surface are likely iron oxides, which should be the debris from the worn disk. In contrast, the wear scars are much smaller and smoother when lubricated by the waterbased nanolubricants, suggesting enhanced anti-wear ability. The boundaries of the wear scars are much cleaner with less adhered impurities too. 

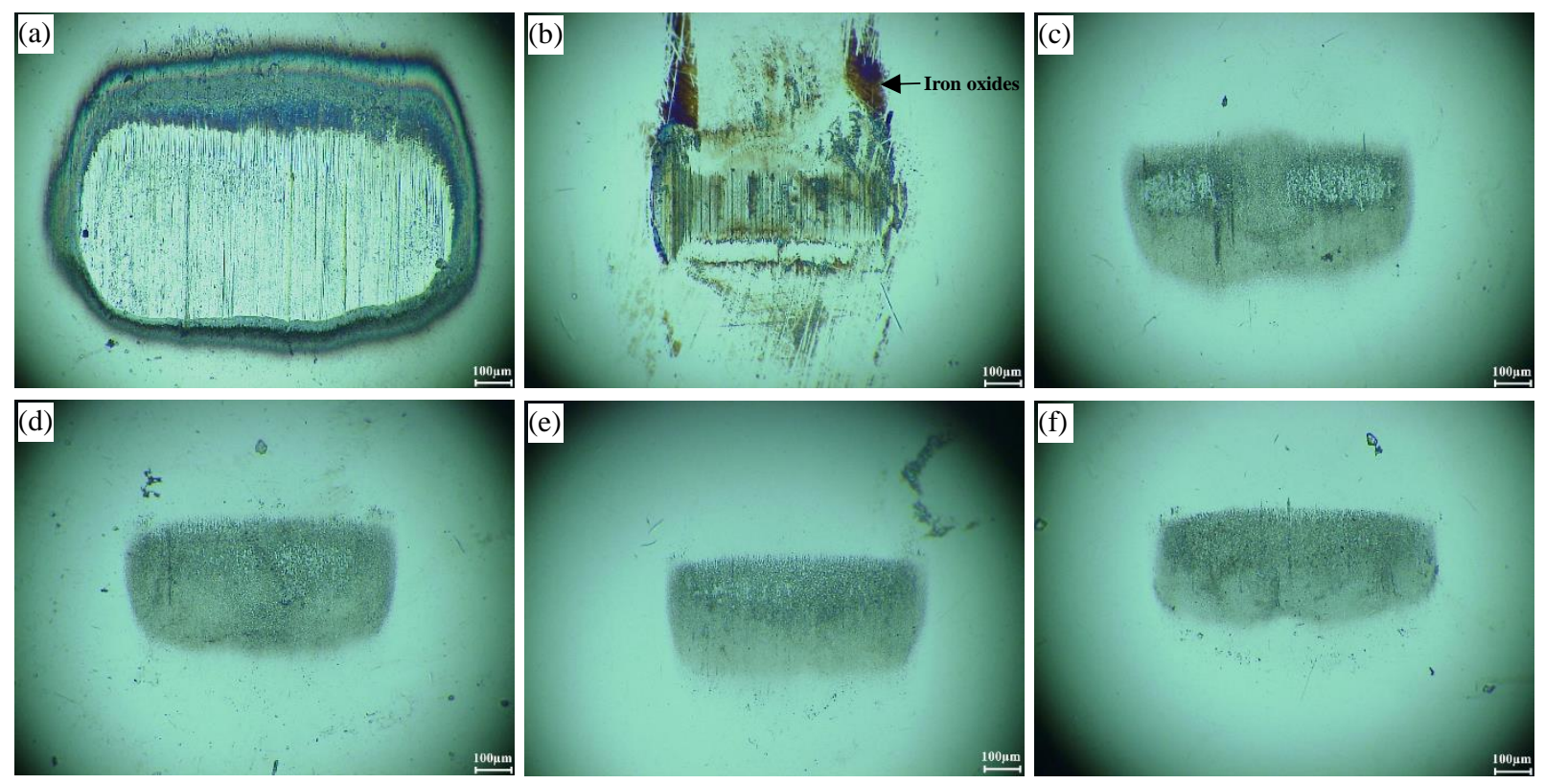

Fig. 4 Surface morphologies of the worn balls obtained at ambient temperature under lubrication conditions of (a) dry, (b) water, (c) $0.4 \mathrm{wt} \% \mathrm{TiO}_{2}$, (d) $1.0 \mathrm{wt} \% \mathrm{TiO}_{2}$, (e) $4.0 \mathrm{wt} \% \mathrm{TiO}_{2}$, and (f) $8.0 \mathrm{wt} \% \mathrm{TiO}_{2}$.

Fig. 5 shows the 3D images and corresponding cross-sectional profiles of the ball wear areas obtained at ambient temperature under different lubrication conditions, whose surface morphologies can be found in Fig. 4. It is observed in Fig. 5(a) and (b) that dry condition brings forth a relatively deep wear scar with a wear area of $2128 \mu \mathrm{m}^{2}$ along $\mathrm{Z}$ axis (depth), while pure water yields a shallower one with a smaller wear area of $1242 \mu \mathrm{m}^{2}$. Apparently, the tests under both dry and water conditions lead to considerable ball wear. The use of nanolubricants results in significantly shallower wear scar with much smaller wear areas than those under dry and water lubrication. In particular, using the nanolubricant containing $4.0 \mathrm{wt} \% \mathrm{TiO}_{2}$ produces the smallest ball wear area of $372 \mu \mathrm{m}^{2}$ (see Fig. 5(e)), which decreases the ball wear by $82.5 \%$ in comparison to the dry condition. Nevertheless, the use of a higher concentration of $8.0 \mathrm{wt} \% \mathrm{TiO}_{2}$ appears to have slightly aggravated the ball wear (see Fig. 5(f)). 

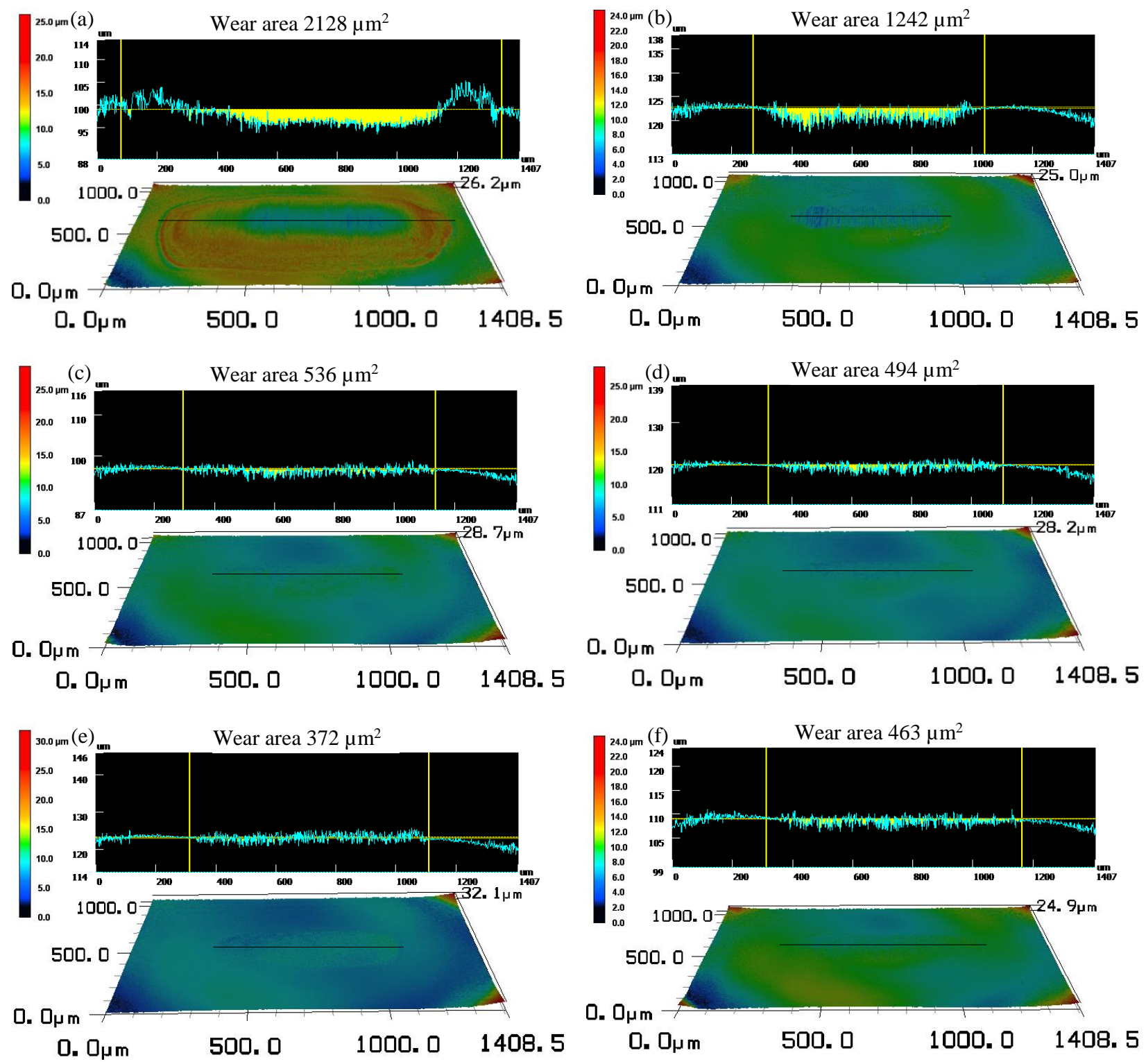

Fig. 5 3D images and corresponding cross-sectional profiles of the ball wear areas obtained at ambient temperature under lubrication conditions of (a) dry, (b) water, (c) $0.4 \mathrm{wt} \% \mathrm{TiO}_{2}$, (d) $1.0 \mathrm{wt} \% \mathrm{TiO}_{2}$, (e) 4.0 $\mathrm{wt} \% \mathrm{TiO}_{2}$, and (f) $8.0 \mathrm{wt} \% \mathrm{TiO}_{2}$. 


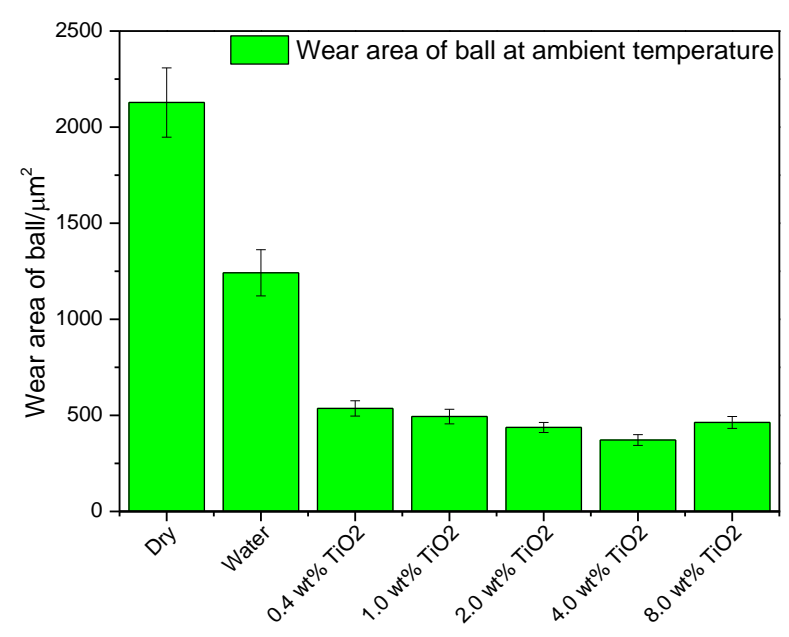

Fig. 6 Wear areas of the balls obtained at ambient temperature under different lubrication conditions.

\subsection{Ball-on-disk tests at $200{ }^{\circ} \mathrm{C}$}

Fig. 7 shows the COF curves and values measured at $200{ }^{\circ} \mathrm{C}$ under different lubrication conditions. It can be seen from Fig. 7(a) that general running-in periods last a bit longer, and overall fluctuations of COF curves are more significant, compared to those in Fig. 3(a). Similarly, dry condition presents the highest COF level, followed by that of water lubrication. The COF curve caused by the nanolubricant containing $0.4 \mathrm{wt} \%$ nano- $\mathrm{TiO}_{2}$ fluctuates severely in the first 160 seconds, and then keeps stable until the end. With the increase of nano- $\mathrm{TiO}_{2}$ concentration in the lubricant, the period with curve fluctuation is increasingly shortened. In order to differentiate the levels of COF curves in Fig. 7(a), averaged COF values extracted from stable stages are shown in Fig. 7(b). It is found that the variation trend of COF values is similar to that in Fig. 3(b), showing an optimal concentration $(4.0 \mathrm{wt} \%)$ of nano- $\mathrm{TiO}_{2}$. It is of great interest that the nanolubricants contribute to much lower COF values at $200{ }^{\circ} \mathrm{C}$ than those obtained at ambient temperature, when the nano- $\mathrm{TiO}_{2}$ concentration is higher than $1.0 \mathrm{wt} \%$. For the same optimal nano- $\mathrm{TiO}_{2}$ concentration of $4.0 \mathrm{wt} \%$, the COF can be reduced by $28.6 \%$ from ambient temperature to the elevated temperature of $200{ }^{\circ} \mathrm{C}$. The COF entailed by dry condition at $200{ }^{\circ} \mathrm{C}$ is thus reduced by $58.9 \%$ to the largest extent when using the nanolubricant containing $4.0 \mathrm{wt} \%$ nano- $\mathrm{TiO}_{2}$. 

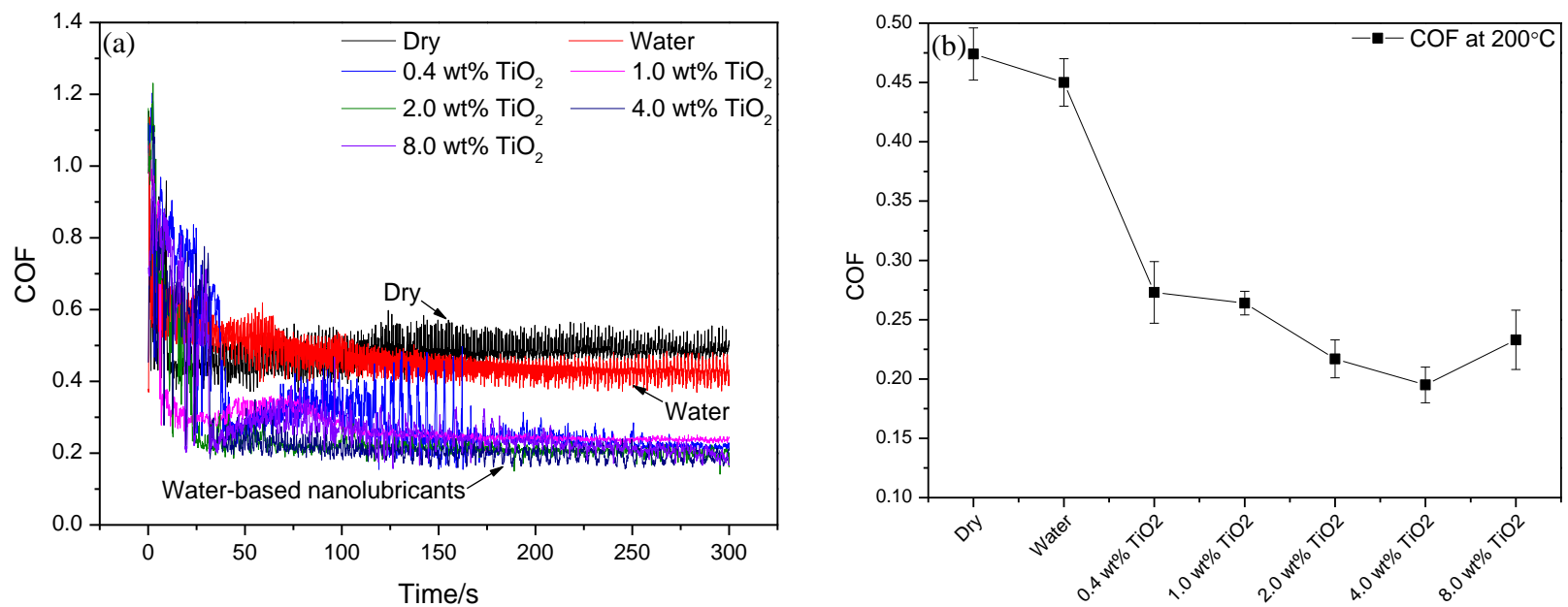

Fig. 7 (a) COF curves as functions of sliding time, and (b) averaged COF values at the stable sliding stage for all the testing conditions at $200{ }^{\circ} \mathrm{C}$.

Fig. 8 shows the surface morphologies of the worn balls obtained at $200{ }^{\circ} \mathrm{C}$ under different lubrication conditions. The wear scar obtained under dry condition is the biggest among all the worn balls. The wear scar caused by water has apparent scratches, and there are abundant black iron oxides adhered to the surroundings. It is acknowledged that these iron oxides are formed when the water contacts the steel surface at $200{ }^{\circ} \mathrm{C}$. The adhered iron oxides can be found around the wear scar with nanolubricant containing 0.4 $\mathrm{wt} \% \mathrm{TiO}_{2}$, above which the worn ball surfaces become smoother and cleaner.
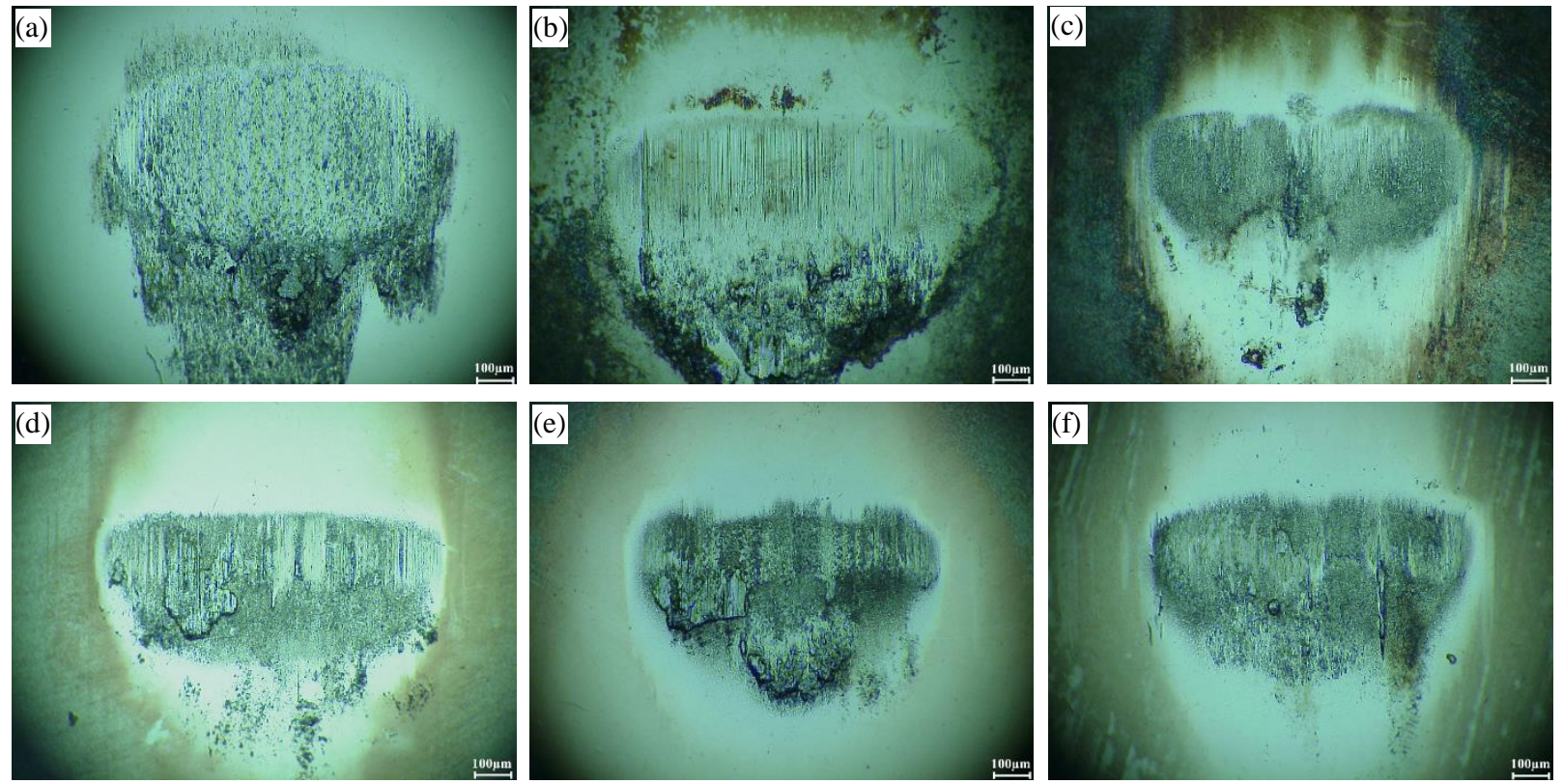

Fig. 8 Surface morphologies of the worn balls obtained at $200{ }^{\circ} \mathrm{C}$ under lubrication conditions of (a) dry, (b) water, (c) $0.4 \mathrm{wt} \% \mathrm{TiO}_{2}$, (d) $1.0 \mathrm{wt} \% \mathrm{TiO}_{2}$, (e) $4.0 \mathrm{wt} \% \mathrm{TiO}_{2}$, and (f) $8.0 \mathrm{wt} \% \mathrm{TiO}_{2}$. 
Fig. 9 shows the 3D images and corresponding cross-sectional profiles of the ball wear areas obtained at $200{ }^{\circ} \mathrm{C}$ under different lubrication conditions, which refers to the surface morphologies of the worn balls shown in Fig. 8. It is similar to the results in Fig. 5 that the dry and water condition produce the most severe ball wear in terms of the wear areas along $\mathrm{Z}$ axis (depth) at $200{ }^{\circ} \mathrm{C}$, which are slightly larger than those obtained at ambient temperature. Another similar result is that the ball wear area continues to decrease until it reaches the smallest value $\left(310 \mu \mathrm{m}^{2}\right)$ with the increase of nano- $\mathrm{TiO}_{2}$ concentration up to $4.0 \mathrm{wt} \%$, followed by a bit larger ball wear area of $322 \mu \mathrm{m}^{2}$ when using $8.0 \mathrm{wt} \% \mathrm{TiO}_{2}$. In this case, the ball wear caused dry condition can be maximally reduced by $88.1 \%$. The variation trend of ball wear areas obtained at $200{ }^{\circ} \mathrm{C}$ is shown in Fig. 10. It can be seen that the ball wear is less severe than that obtained at ambient temperature when the nano- $\mathrm{TiO}_{2}$ concentration is above $0.4 \mathrm{wt} \%$. 

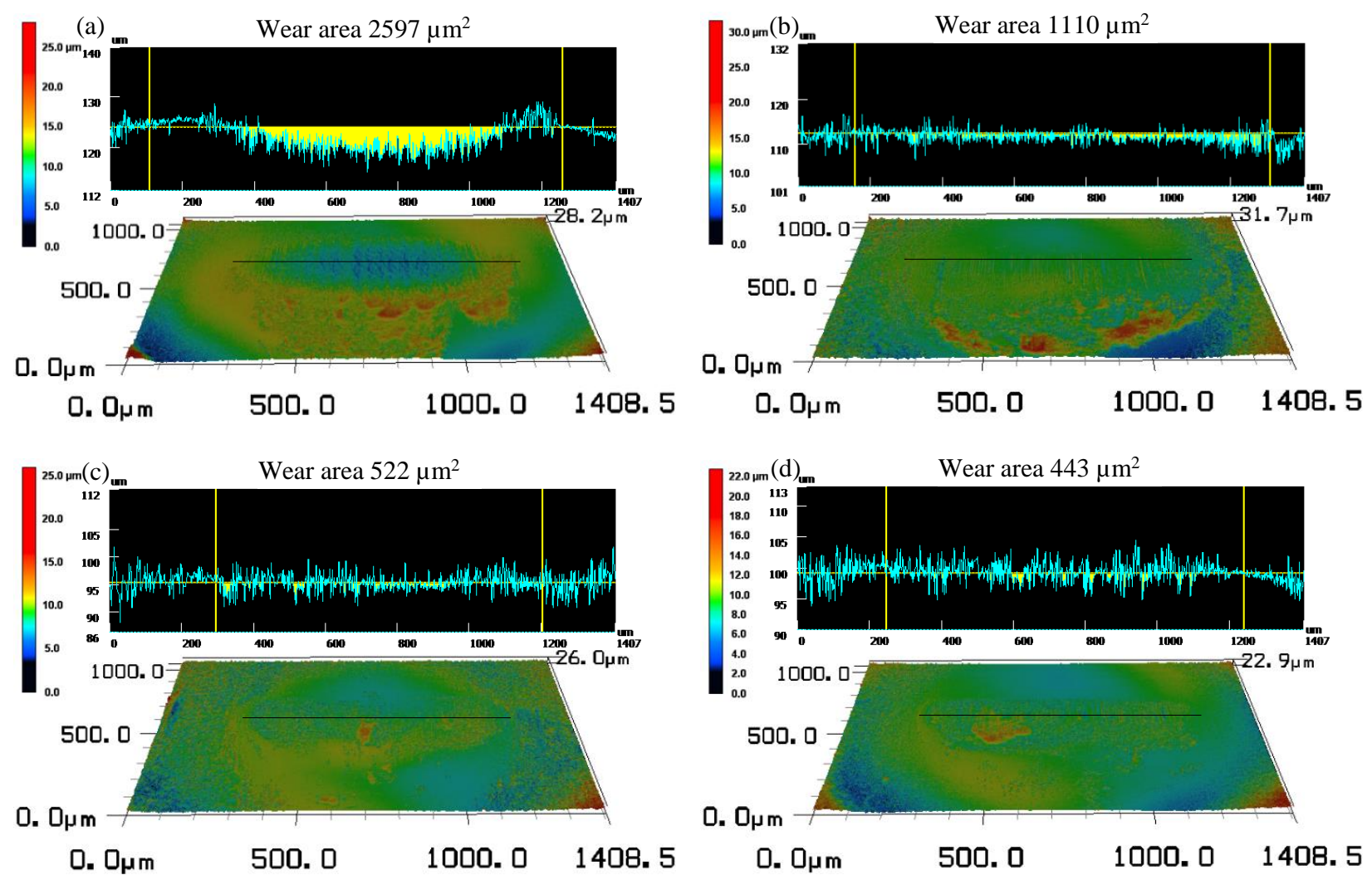

0. $0 \mu \mathrm{m}$ 500. 0
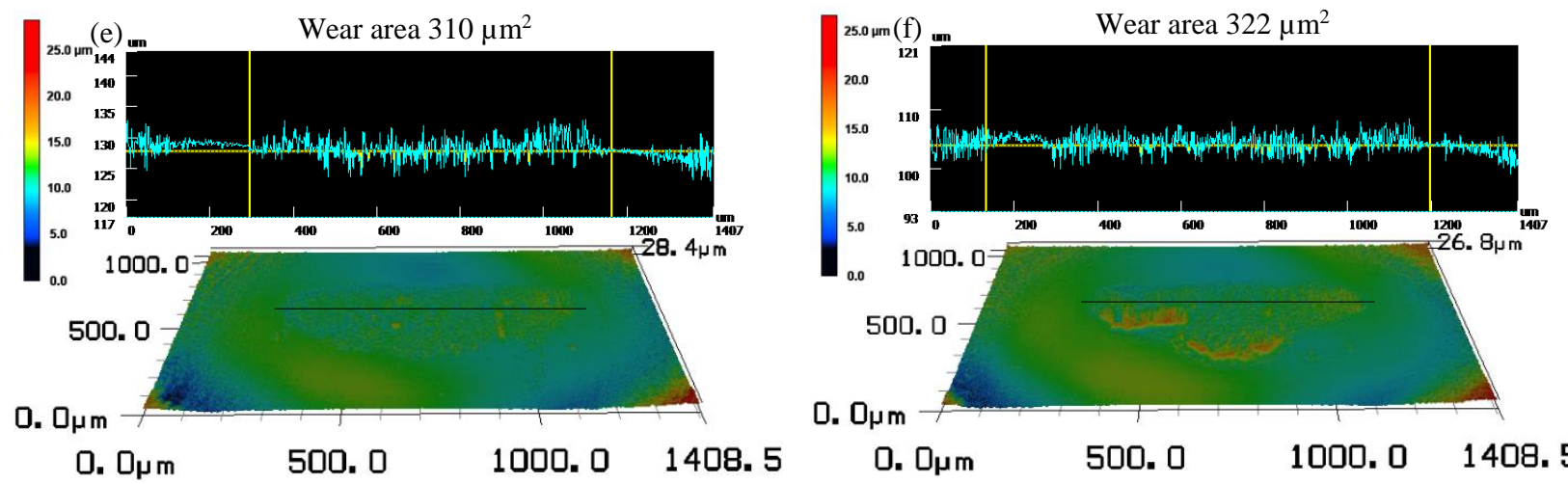

Fig. $93 \mathrm{D}$ images and corresponding cross-sectional profiles of the ball wear areas obtained at $200{ }^{\circ} \mathrm{C}$ under lubrication conditions of (a) dry, (b) water, (c) $0.4 \mathrm{wt} \% \mathrm{TiO}_{2}$, (d) $1.0 \mathrm{wt} \% \mathrm{TiO}_{2}$, (e) $4.0 \mathrm{wt} \% \mathrm{TiO}_{2}$, and (f) $8.0 \mathrm{wt} \% \mathrm{TiO}_{2}$. 


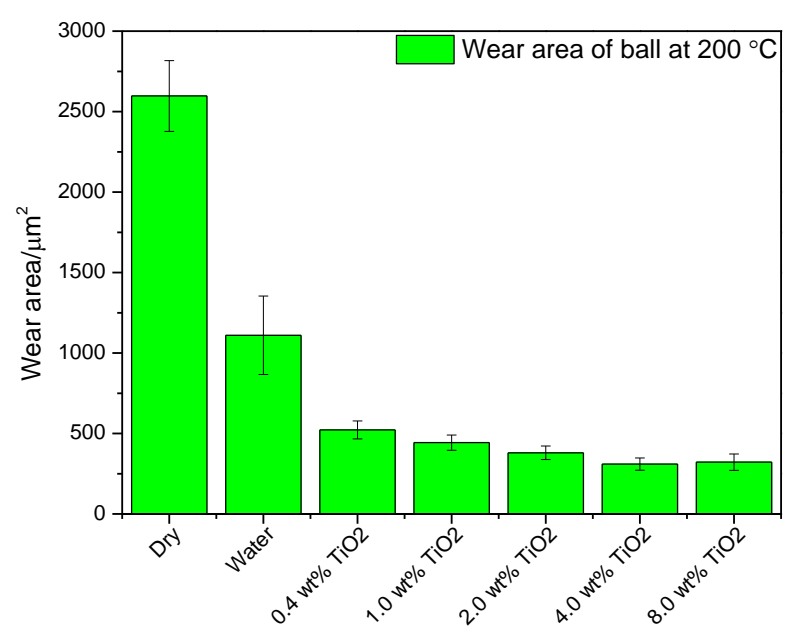

Fig. 10 Wear areas of the balls obtained at $200{ }^{\circ} \mathrm{C}$ under different lubrication conditions.

\subsection{Ball-on-disk tests at $500{ }^{\circ} \mathrm{C}$}

Fig. 11 shows the $\mathrm{COF}$ curves and values measured at $500{ }^{\circ} \mathrm{C}$ under different lubrication conditions. As can be seen from Fig. 11(a) that the overall running-in periods are much longer than those at ambient temperature and $200{ }^{\circ} \mathrm{C}$ (see Figs. 3(a) and 7(a)), and the $\mathrm{COF}$ curves caused by 4.0 and $8.0 \mathrm{wt} \% \mathrm{TiO}_{2}$ appear to be more fluctuant than those caused by other lubrication conditions. The variation of averaged COF values obtained from the stable stages is shown in Fig. 11(b). It is similar to the trends in Figs. 3(b) and 7(b) that the nanolubricant containing $4.0 \mathrm{wt} \% \mathrm{TiO}_{2}$ enables the maximal $\mathrm{COF}$ reduction by $39.5 \%$ based on that of dry condition. The difference is that the highest concentration of $8.0 \mathrm{wt} \% \mathrm{TiO}_{2} \mathrm{increases}$ the $\mathrm{COF}$ value to the utmost among all the nanolubricants.
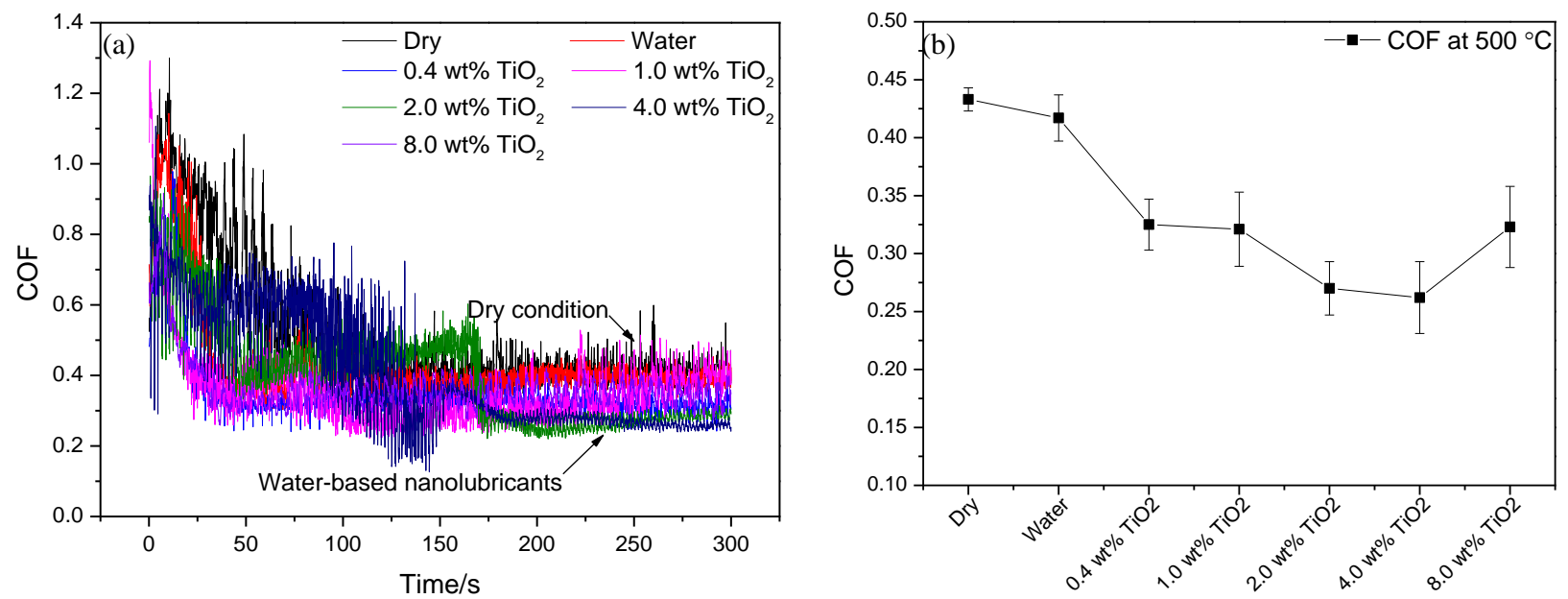

Fig. 11 (a) COF curves as functions of sliding time, and (b) averaged COF values at the stable sliding stage for all the testing conditions at $500{ }^{\circ} \mathrm{C}$. 
Fig. 12 shows the surface morphologies of the worn balls obtained at $500{ }^{\circ} \mathrm{C}$ under different lubrication conditions. It is observed that the wear scars produced by water and water-based nanolubricants are wider than that produced under dry condition. The sticking phenomenon of the ball only occurs when lubricated by water. The apparent scratches appear after water and $0.4 \mathrm{wt} \% \mathrm{TiO}_{2}$ are used in the sliding process. In contrast, the nanolubricants containing an even higher concentration of nano- $\mathrm{TiO}_{2}$ lead to smoother wear scars. In particular, the wear scar caused by $4.0 \mathrm{wt} \% \mathrm{TiO}_{2}$ is the smallest (see Fig.12 (e)), while the one produced by $8.0 \mathrm{wt} \% \mathrm{TiO}_{2}$ becomes the biggest instead (see Fig.12 (f)).
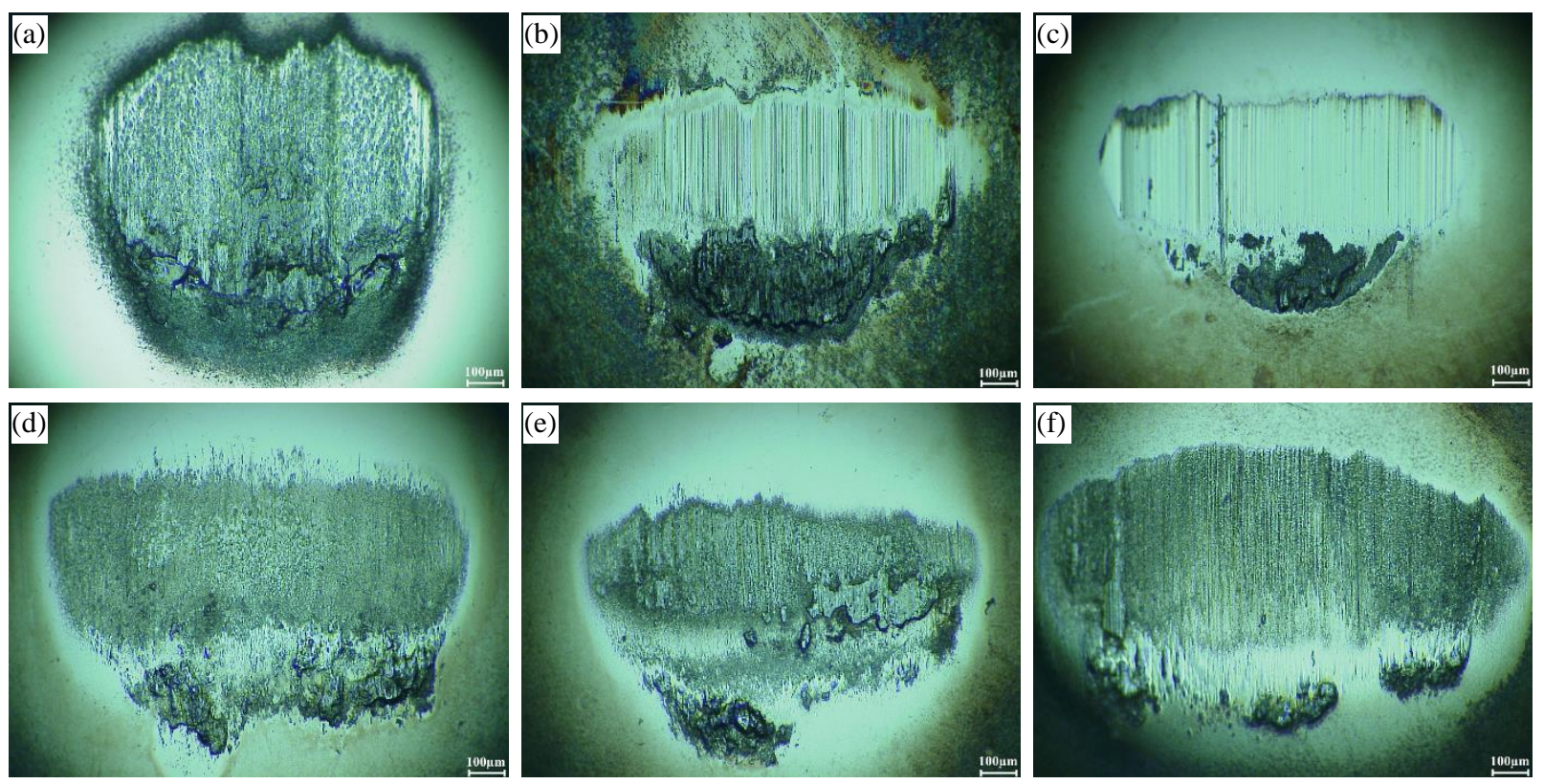

Fig. 12 Surface morphologies of the worn balls obtained at $500{ }^{\circ} \mathrm{C}$ under lubrication conditions of (a) dry, (b) water, (c) $0.4 \mathrm{wt} \% \mathrm{TiO}_{2}$, (d) $1.0 \mathrm{wt} \% \mathrm{TiO}_{2}$, (e) $4.0 \mathrm{wt} \% \mathrm{TiO}_{2}$, and (f) $8.0 \mathrm{wt} \% \mathrm{TiO}_{2}$.

Fig. 13 shows the 3D images and corresponding cross-sectional profiles of the ball wear areas obtained at $500{ }^{\circ} \mathrm{C}$ under different lubrication conditions, such as dry, $0.4,4.0$ and $8.0 \mathrm{wt} \% \mathrm{TiO}_{2}$. It can be seen that the balls are significantly worn out under both dry condition and $0.4 \mathrm{wt} \% \mathrm{TiO}_{2}$ in terms of the wear areas along $\mathrm{Z}$ axis (depth) at $500{ }^{\circ} \mathrm{C}$, which are much larger than those obtained at ambient temperature and $200{ }^{\circ} \mathrm{C}$ (see Figs. 5 and 9). The ball wear can be greatly alleviated by using the nanolubricant containing $4.0 \mathrm{wt} \% \mathrm{TiO}_{2}$, instead of being aggravated when the nano- $\mathrm{TiO}_{2}$ concentration increases to $8.0 \mathrm{wt} \%$. The wear areas of the balls yielded at $500{ }^{\circ} \mathrm{C}$ under applied lubrication conditions are quantitatively shown in Fig. 14. The results indicate that the ball wear produced under dry condition can be minimised by $85.5 \%$ when using the nanolubricant containing $4.0 \mathrm{wt} \% \mathrm{TiO}_{2}$. 

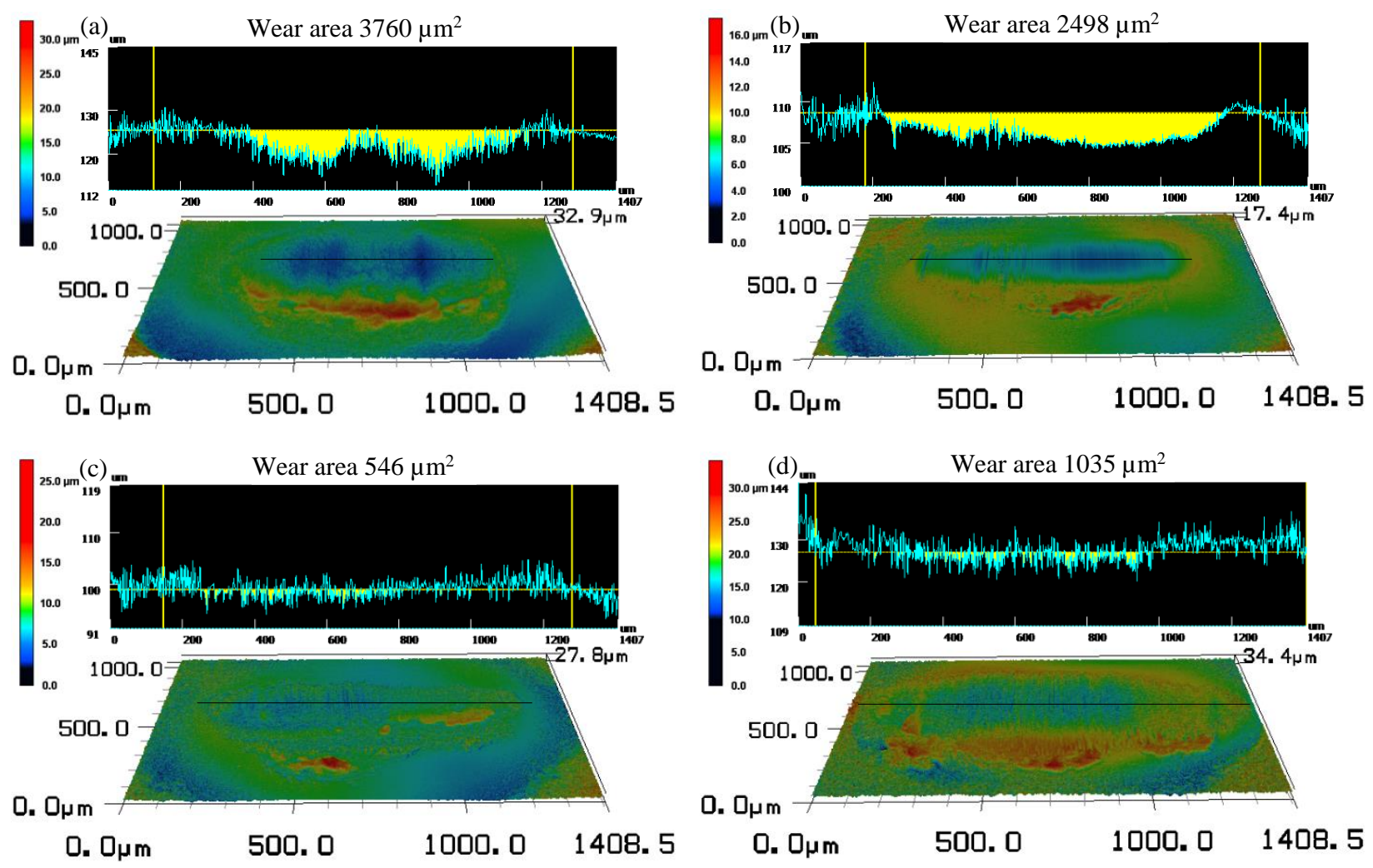

Fig. 13 3D images and corresponding cross-sectional profiles of the ball wear areas obtained at $500{ }^{\circ} \mathrm{C}$ under lubrication conditions of (a) dry, (b) $0.4 \mathrm{wt} \% \mathrm{TiO}_{2}$, (c) $4.0 \mathrm{wt} \% \mathrm{TiO}_{2}$, and (d) $8.0 \mathrm{wt} \% \mathrm{TiO}_{2}$.

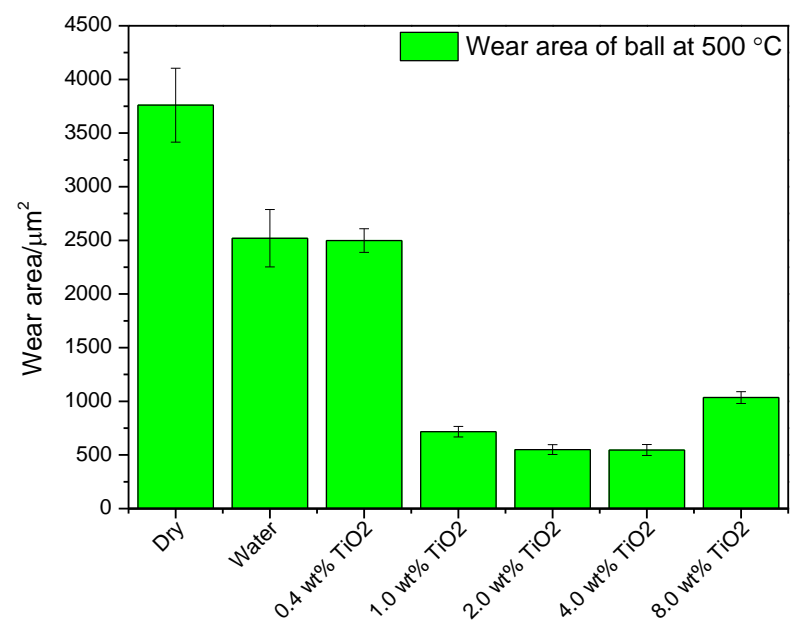

Fig. 14 Wear areas of the balls obtained at $500{ }^{\circ} \mathrm{C}$ under different lubrication conditions. 


\section{Discussion}

\subsection{Rolling and polishing effects}

As shown in Fig. 15(a)-(d), the SEM images of worn disk surfaces using the nanolubricants containing 0.4, 1.0, 4.0 and $8.0 \mathrm{wt} \% \mathrm{TiO}_{2}$, respectively. The EDS spectra acquired from Area A in Fig. 15(c) and Area B in Fig. 15(d) are shown in Fig. 15(e) and (f), respectively, demonstrating that $\mathrm{TiO}_{2} \mathrm{NPs}$ are distributed in the wear tracks. As the $\mathrm{TiO}_{2}$ NPs have spherical shapes, they could serve as rollers between the ball and the disk to reduce friction, at the same time polish the surfaces [44]. This is likely why the COF and ball wear are significantly reduced in comparison to the respective values obtained from dry and pure water conditions. Also, smoother surfaces of worn balls are produced, as can be seen in Figs. 3-6. The NPs that effectively rub surfaces should be originated from two sources, those trapped in surface valleys and existed outside contact region [23]. For the nanolubricant containing the lowest nano- $\mathrm{TiO}_{2}$ concentration of 0.4 $\mathrm{wt} \%$, few $\mathrm{TiO}_{2}$ NPs act inside the contact region, thus limit their contribution to the reduction of COF and ball wear. With progressively increasing the nano- $\mathrm{TiO}_{2}$ concentration up to $4.0 \mathrm{wt} \%$, an increasing number of $\mathrm{TiO}_{2} \mathrm{NPs}_{\text {are }}$ trapped in the disk valleys due to the presence of initial scratches over the disk surface (see Fig. 1(c) and (d)). These trapped $\mathrm{TiO}_{2}$ NPs and supplementary ones can be furnished from the valleys and the outer region, respectively, onto the rubbing surfaces. This relieves NP starvation and thus improves the friction-reduction and anti-wear abilities, leading to a declining trend of the COF and ball wear [45-47]. When $\mathrm{TiO}_{2} \mathrm{NPs}$ are excessive, such as the case of $8.0 \mathrm{wt} \%$, the $\mathrm{TiO}_{2} \mathrm{NPs}_{\text {are }}$ sparsely populated in the wear track. This is because the NPs can accumulate around the contact region to form a barrier, which reduces the extraneous supply of NPs from the outer region [48]. Moreover, the NPs tend to agglomerate and hence increase their size. Both the block of NPs into the contact region and agglomerated NPs would aggravate the friction and wear [49], and therefore result in a higher COF and more severe ball wear, compared to those of $4.0 \mathrm{wt} \% \mathrm{TiO}_{2}$. 

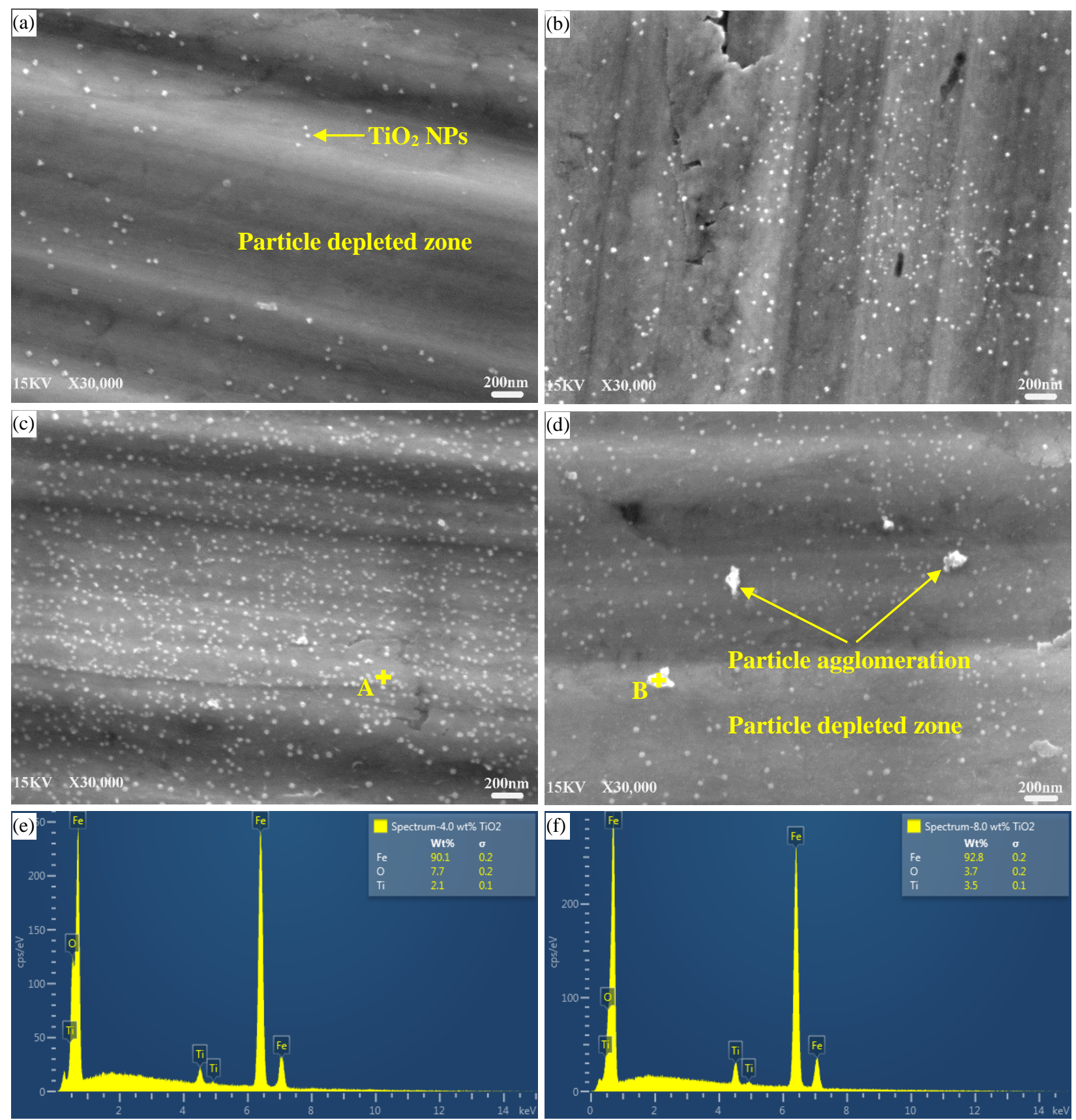

Fig. 15 SEM images of worn disk surfaces lubricated by (a) $0.4 \mathrm{wt} \% \mathrm{TiO}_{2}$, (b) $1.0 \mathrm{wt} \% \mathrm{TiO}_{2}$, (c) $4.0 \mathrm{wt} \%$ $\mathrm{TiO}_{2}$, and (d) $8.0 \mathrm{wt} \% \mathrm{TiO}_{2}$, and EDS spectra of (e) $4.0 \mathrm{wt} \% \mathrm{TiO}_{2}$ and (f) $8.0 \mathrm{wt} \% \mathrm{TiO}_{2}$. 


\subsection{Effect of nanoparticles at elevated temperatures}

Fig. 16 shows the SEM images and EDS mappings of the worn disk surfaces using the nanolubricants containing 0.4, 1.0, 4.0 and $8.0 \mathrm{wt} \% \mathrm{TiO}_{2}$ at the elevated temperature of $200{ }^{\circ} \mathrm{C}$. It is found from Fig. 16 (a) that $\mathrm{TiO}_{2}$ NPs are scarcely distributed in the wear track, indicating that NPs may have played similar lubrication effect to that at ambient temperature. In contrast, small pieces of $\mathrm{TiO}_{2}$ films that have loose microstructures are found to be deposited in the wear track when the nano- $\mathrm{TiO}_{2}$ concentration increases to $1.0 \mathrm{wt} \%$ (see Fig. 16(b)). Such a lubricating film is observed over the entire wear track when the nano- $\mathrm{TiO}_{2}$ concentration increases to $4.0 \mathrm{wt} \%$, as shown in Fig. 16(c). The lubricating film appears like a type of "semisolid film" that consists of $\mathrm{TiO}_{2}$ NPs and glycerol, since the water is expected to be fully evaporated at $200{ }^{\circ} \mathrm{C}$, while glycerol has a much higher boiling temperature of $290{ }^{\circ} \mathrm{C}$ [50]. As glycerol is a viscous liquid, this semisolid film is supposed to have similar lubrication effect to the protective film formed by the

oil containing NPs, which greatly facilitates the decrease of COF and ball wear [51, 52]. A further increase of nano- $\mathrm{TiO}_{2}$ concentration to $8.0 \mathrm{wt} \%$ would enhance the semisolid film, i.e. the film becomes thicker and denser, as shown in Fig. 16(d). However, a thicker and denser film may impede the movement of the ball, and thus lead to a higher COF than that of $4.0 \mathrm{wt} \% \mathrm{TiO}_{2}$. Nevertheless, the ball wear is not deteriorated significantly, as the semisolid film can prevent the ball from direct contact with the disk. The semisolid film formed at $200{ }^{\circ} \mathrm{C}$ is expected to improve the tribological performance, also alleviate the sticking phenomenon occurred on the ball surface, as shown in Fig. 8.

It should be noted that the iron oxides are inevitably generated, especially when the water-based lubricants contact the hot disks at $200{ }^{\circ} \mathrm{C}$. The EDS mappings of the element oxygen shown in Fig. 16 are also indicative of iron oxides other than $\mathrm{TiO}_{2}$ NPs. It has been reported that oxidation of the steel surfaces leads to low friction and mild wear, irrespective of the initial lubrication condition [53,54]. In the cases of pure water and water-based nanolubricants, the contribution of generated iron oxides to the friction and wear is deemed nearly identical, since water is the main composition in the lubricant. For water-based

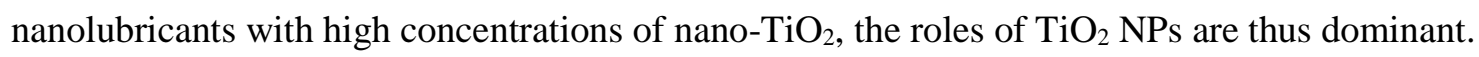



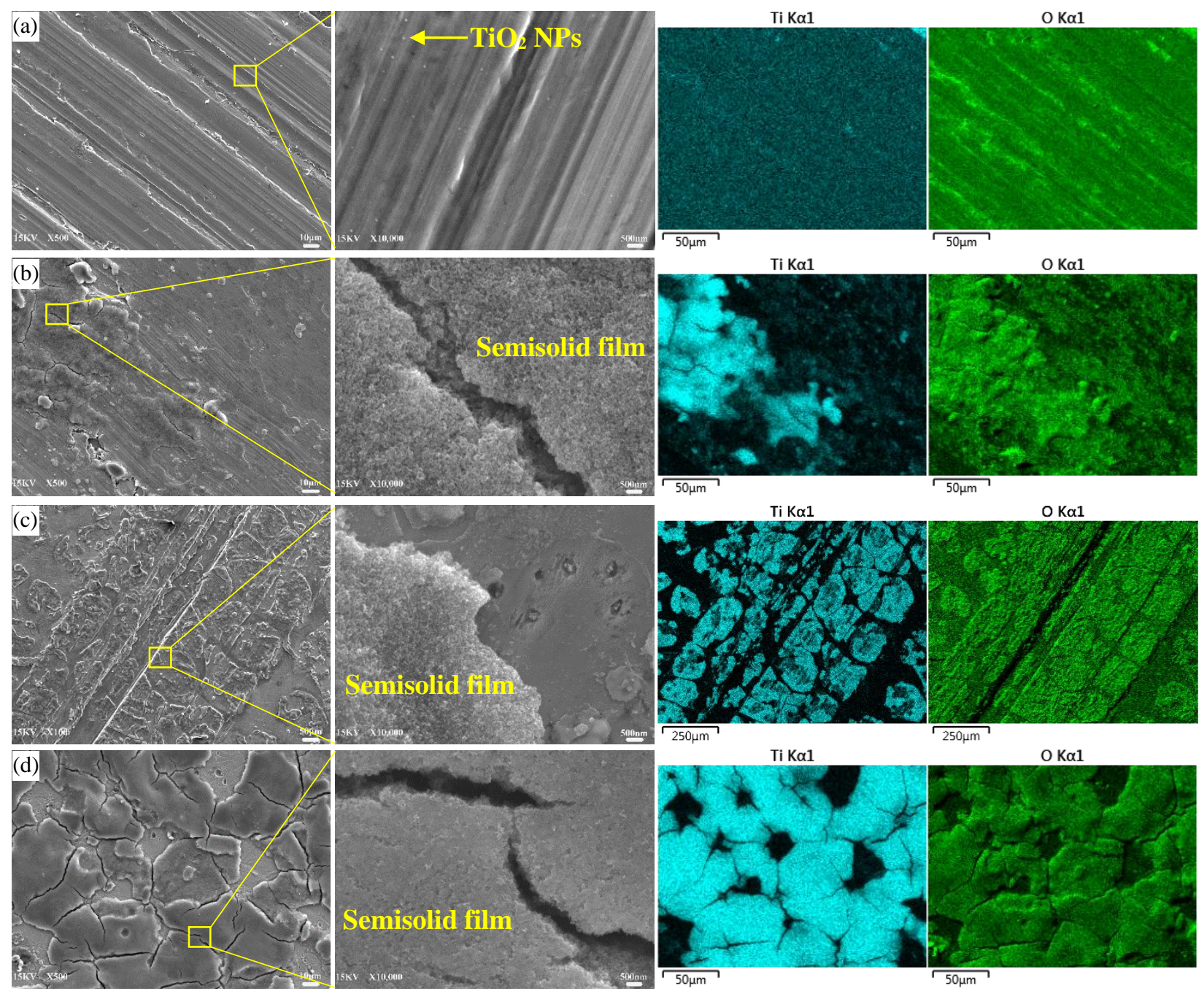

Fig. 16 SEM images and EDS mappings of the worn disk surfaces lubricated by (a) 0.4 wt $\% \mathrm{TiO}_{2}$, (b) 1.0 $\mathrm{wt} \% \mathrm{TiO}_{2}$, (c) $4.0 \mathrm{wt} \% \mathrm{TiO}_{2}$, and (d) $8.0 \mathrm{wt} \% \mathrm{TiO}_{2}$ at $200{ }^{\circ} \mathrm{C}$.

Fig. 17 shows the SEM images and EDS mappings of the worn disk surfaces with the nanolubricants containing $0.4,4.0$ and $8.0 \mathrm{wt} \% \mathrm{TiO}_{2}$ at $500{ }^{\circ} \mathrm{C}$. It is seen from Fig. 17 (a) that there is a cluster of $\mathrm{TiO}_{2} \mathrm{NPs}$ and iron oxides scattered in the wear track, which greatly aggravates the friction and wear, and thus produces apparent scratches on the ball surface (see Fig. 12(c)) with severe ball wear (see Fig. 13(b)). When the nano- $\mathrm{TiO}_{2}$ concentration increases to $4.0 \mathrm{wt} \%$, the wear track is completely covered by a solid layer that is only composed of loose $\mathrm{TiO}_{2}$ NPs (see Fig. 17(b)). This is because both water and glycerol are vaporised at $500{ }^{\circ} \mathrm{C}$, the $\mathrm{TiO}_{2} \mathrm{NPs}$ thus form the solid layer under the pressure of contact between the ball and disk. The loose $\mathrm{TiO}_{2}$ layer behaves like a coating layer on the rubbing surface, which prevents metal surfaces from direct contact, and therefore improves the lubrication performance $[2,55]$. In contrast, the nanolubricant containing $8.0 \mathrm{wt} \% \mathrm{TiO}_{2}$ appears to have formed a very compact solid layer under the elevated temperature of $500{ }^{\circ} \mathrm{C}$, as shown in Fig. 17(c). As the compact layer is harder than the loose one, 
the ball lubricated by $8.0 \mathrm{wt} \% \mathrm{TiO}_{2}$ thus suffers more severe wear than that lubricated by $4.0 \mathrm{wt} \% \mathrm{TiO}_{2}$. Besides, the $\mathrm{TiO}_{2}$ NPs agglomerated around the contact region could cause extra friction on the rubbing surfaces [23], leading to a higher COF and a wider wear scar of the ball, compared to those of $4.0 \mathrm{wt} \%$ $\mathrm{TiO}_{2}$. With the temperature increases from 200 to $500{ }^{\circ} \mathrm{C}$, therefore, the increased COF and ball wear are dependent on a transfer from metal-on-semisolid film contact to metal-on-solid layer contact. It is similar to the case happened at $200{ }^{\circ} \mathrm{C}$ that the $\mathrm{TiO}_{2} \mathrm{NPs}$ dominate the contribution to improve the tribological properties of water-based nanolubricants.
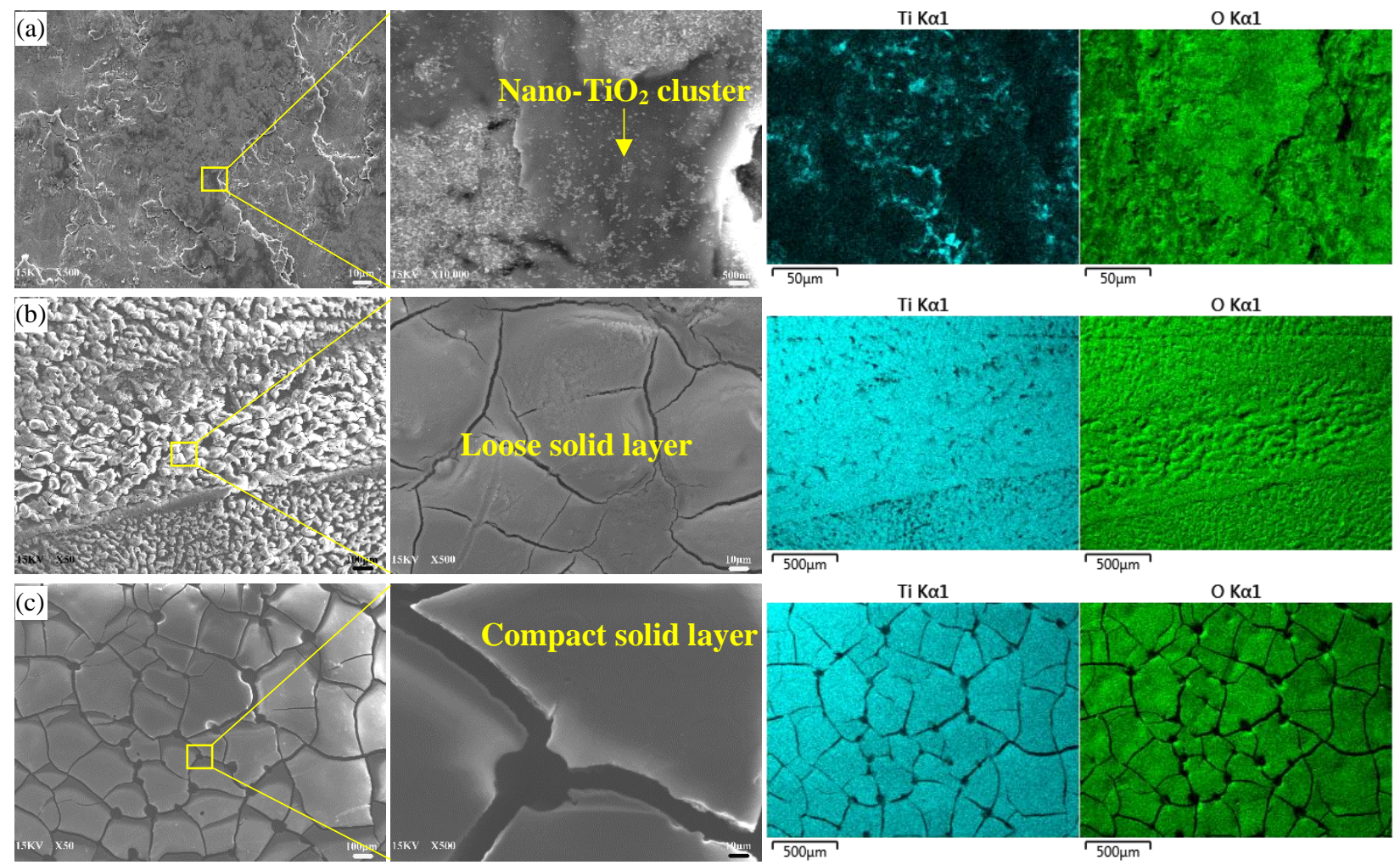

Fig. 17 SEM images and EDS mappings of the worn disk surfaces lubricated by (a) 0.4 wt $\% \mathrm{TiO}_{2}$, (b) 4.0 $\mathrm{wt} \% \mathrm{TiO}_{2}$, and (c) $8.0 \mathrm{wt} \% \mathrm{TiO}_{2}$ at $500{ }^{\circ} \mathrm{C}$. 


\subsection{Friction and wear mechanisms}

Fig. 18 schematically illustrates the friction and wear mechanisms involved in the ball-on-disk tests at ambient and elevated temperatures using the water-based nanolubricants. When the $\mathrm{Cr}$ steel ball slides against the relatively rough mild steel disk at ambient temperature (see Fig. 18(a)), the spherical $\mathrm{TiO}_{2} \mathrm{NPs}$ suspended in the lubricant play the roles of ball bearings in the contact region, so their rolling and polishing effects enable the reduction of COF between the rubbing surfaces, and thus decrease the ball wear. Because the disk surface has machined striations, $\mathrm{TiO}_{2} \mathrm{NPs}$ can be trapped in the valleys working together with the NPs supplemented from the outer region. With the nano- $\mathrm{TiO}_{2}$ concentration increases from 0.4 to $4.0 \mathrm{wt} \%$, there is an increasing number of effective $\mathrm{TiO}_{2} \mathrm{NPs}$ behaving in the contact region, indicating progressively improved lubrication performance. However, a further increase of nano- $\mathrm{TiO}_{2}$ concentration up to $8.0 \mathrm{wt} \%$ may accelerate the agglomeration of $\mathrm{TiO}_{2} \mathrm{NPs}$. This thus promotes the formation of a barrier that blocks the continuous supply of $\mathrm{TiO}_{2}$ NPs from the outer region, leading to the increased COF and ball wear. The lubrication mechanisms at $200{ }^{\circ} \mathrm{C}$ are somehow different from those at the ambient temperature, which are associated with the formation of a semisolid film that consists of $\mathrm{TiO}_{2} \mathrm{NPs}$ and glycerol, as shown in Fig. 18(b). The semisolid film prevents the ball from direct contact with the disk, thereby decreasing the friction and ball wear. A maximal nano- $\mathrm{TiO}_{2}$ concentration of $8.0 \mathrm{wt} \%$, however, results in a thickened semisolid film, which may impede the movement of the ball and thus increase the COF. When the disk is further heated up to $500{ }^{\circ} \mathrm{C}$, the semisolid film is transformed to a solid layer which covers the entire disk surface, as shown in Fig. 18(c). As the solid layer is only composed of $\mathrm{TiO}_{2} \mathrm{NPs}$ which is harder than the semisolid film, this would result in higher COF values and more severe ball wear, compared to those caused by the semisolid film formed at $200^{\circ} \mathrm{C}$. 

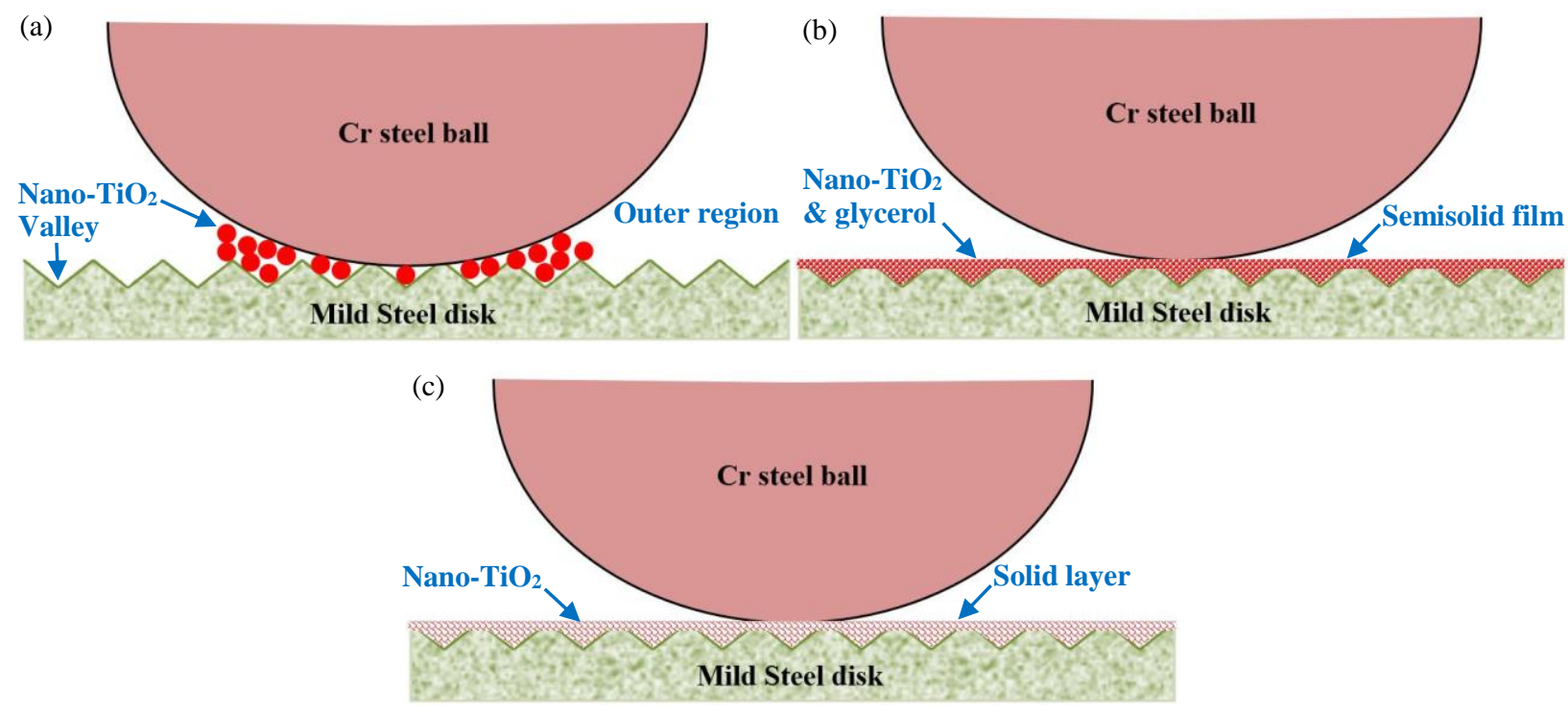

Fig. 18 Schematic illustration of friction and wear mechanisms using the water-based nanolubricants at (a) ambient temperature, (b) $200{ }^{\circ} \mathrm{C}$ and (c) $500{ }^{\circ} \mathrm{C}$.

\section{Conclusions}

In this study, ball-on-disk tribological tests were conducted at ambient and elevated temperatures of 200 and $500{ }^{\circ} \mathrm{C}$ using the water-based nanolubricants containing different nano- $\mathrm{TiO}_{2}$ concentrations from 0.4 to $8.0 \mathrm{wt} \%$. The friction and wear behaviours of the chrome steel ball were investigated in terms of the COF and wear area of the ball. The conclusions are drawn as follows.

(1) The use of water-based nanolubricants containing different nano- $\mathrm{TiO}_{2}$ concentrations greatly decreases the COF and ball wear at both ambient and elevated temperatures, in comparison to the benchmark values obtained from the dry and water conditions. The optimal concentration of $4.0 \mathrm{wt} \% \mathrm{TiO}_{2}$ exhibits the best lubrication performance among all the lubrication conditions.

(2) At ambient temperature, the COF and ball wear obtained under dry condition can be decreased by $40 \%$ and $82.5 \%$, respectively, which is ascribed to the rolling and polishing effects contributed by $\mathrm{TiO}_{2} \mathrm{NPs}_{\text {. }}$

(3) At $200{ }^{\circ} \mathrm{C}$, the COF and ball wear obtained under dry condition are decreased by $58.9 \%$ and $88.1 \%$, respectively, due to the formation of a semisolid film that consists of $\mathrm{TiO}_{2} \mathrm{NPs}$ and glycerol.

(4) At $500{ }^{\circ} \mathrm{C}$, the COF and ball wear obtained under dry condition are reduced by $39.5 \%$ and $85.5 \%$, respectively. The lubrication mechanism is dependent on the formation of a solid layer that is only composed of $\mathrm{TiO}_{2}$ NPs. 


\section{Acknowledgements}

The authors acknowledge the financial support from Baosteel-Australia Joint Research and Development Centre (BAJC) under the project of BA17004 and Australian Research Council (ARC) under Linkage Project Program (LP150100591). The authors would like to thank Mr. Suoquan Zhang at Baosteel Research Institute for his kind assistance on the provision of steel samples. The authors are also grateful to the technicians in the workshop of SMART Infrastructure Facility at University of Wollongong for their great supports on samples machining.

\section{References}

[1] J. Zhao, Z. Jiang, Thermomechanical processing of advanced high strength steels, Progress in Materials Science 94 (2018) 174-242.

[2] H.J. Kim, D.G. Shin, D.-E. Kim, Frictional behavior between silicon and steel coated with graphene oxide in dry sliding and water lubrication conditions, International Journal of Precision Engineering and Manufacturing-Green Technology 3(1) (2016) 91-97.

[3] H.-J. Kim, D.-E. Kim, Water Lubrication of Stainless Steel using Reduced Graphene Oxide Coating, Scientific Reports (2015) 17034.

[4] H. Wu, J. Zhao, W. Xia, X. Cheng, A. He, J.H. Yun, L. Wang, H. Huang, S. Jiao, L. Huang, S. Zhang, Z. Jiang, Analysis of TiO2 nano-additive water-based lubricants in hot rolling of microalloyed steel, J. Manuf. Processes 27 (2017) 26-36.

[5] H. Wu, J. Zhao, L. Luo, S. Huang, L. Wang, S. Zhang, S. Jiao, H. Huang, Z. Jiang, Performance Evaluation and Lubrication Mechanism of Water-Based Nanolubricants Containing Nano-TiO2 in Hot Steel Rolling, Lubricants 6(3) (2018) 57.

[6] S. Boyde, Green lubricants. Environmental benefits and impacts of lubrication, Green Chem. 4(4) (2002) 293-307.

[7] F. Haus, J. German, G.-A. Junter, Primary biodegradability of mineral base oils in relation to their chemical and physical characteristics, Chemosphere 45(6) (2001) 983-990.

[8] Y. Fu, A.W. Batchelor, N.K. Loh, K.W. Tan, Effect of lubrication by mineral and synthetic oils on the sliding wear of plasma nitrided AISI 410 stainless steel, Wear 219(2) (1998) 169-176.

[9] J. Sotres, T. Arnebrant, Experimental Investigations of biological lubrication at the nanoscale: the cases of synovial joints and the oral cavity, Lubricants 1(4) (2013) 102-131.

[10] M. Ratoi-Salagean, H. Spikes, H. Rieffe, Optimizing film formation by oil-in-water emulsions, Tribol. Trans. 40(4) (1997) 569-578.

[11] W.R.D. Wilson, Y. Sakaguchi, S.R. Schmid, A dynamic concentration model for lubrication with oil-inwater emulsions, Wear 161(1) (1993) 207-212.

[12] W. Xia, J. Zhao, H. Wu, S. Jiao, X. Zhao, X. Zhang, J. Xu, Z. Jiang, Analysis of oil-in-water based nanolubricants with varying mass fractions of oil and TiO 2 nanoparticles, Wear 396-397 (2018) 162-171.

[13] W. Xia, J. Zhao, H. Wu, X. Zhao, X. Zhang, J. Xu, S. Jiao, X. Wang, C. Zhou, Z. Jiang, Effects of oil-inwater based nanolubricant containing TiO2 nanoparticles in hot rolling of 304 stainless steel, J. Mater. Process. Technol. 262 (2018) 149-156.

[14] W. Xia, J. Zhao, H. Wu, S. Jiao, Z. Jiang, Effects of oil-in-water based nanolubricant containing TiO2 nanoparticles on the tribological behaviour of oxidised high-speed steel, Tribol. Int. 110 (2017) 77-85.

[15] H.J. Kim, I.C. Bang, J. Onoe, Characteristic stability of bare Au-water nanofluids fabricated by pulsed laser ablation in liquids, Opt. Lasers Eng. 47(5) (2009) 532-538. 
[16] C. Zhang, S. Zhang, S. Song, G. Yang, L. Yu, Z. Wu, X. Li, P. Zhang, Preparation and Tribological Properties of Surface-Capped Copper Nanoparticle as a Water-Based Lubricant Additive, Tribol. Lett. 54(1) (2014) 25-33.

[17] S. Radice, S. Mischler, Effect of electrochemical and mechanical parameters on the lubrication behaviour of Al2O3 nanoparticles in aqueous suspensions, Wear 261(9) (2006) 1032-1041.

[18] Y. Gao, G. Chen, Y. Oli, Z. Zhang, Q. Xue, Study on tribological properties of oleic acid-modified TiO2 nanoparticle in water, Wear 252(5) (2002) 454-458.

[19] M.S. Najiha, M.M. Rahman, Experimental investigation of flank wear in end milling of aluminum alloy with water-based TiO2 nanofluid lubricant in minimum quantity lubrication technique, Int. J. Adv. Manuf. Technol. 86(9) (2016) 2527-2537.

[20] L. Gara, Q. Zou, Friction and Wear Characteristics of Water-Based ZnO and Al2O3 Nanofluids, Tribol. Trans. 55(3) (2012) 345-350.

[21] C. Zhao, Y.K. Chen, G. Ren, A Study of Tribological Properties of Water-Based Ceria Nanofluids, Tribol. Trans. 56(2) (2013) 275-283.

[22] A. He, S. Huang, J.-H. Yun, H. Wu, Z. Jiang, J. Stokes, S. Jiao, L. Wang, H. Huang, Tribological Performance and Lubrication Mechanism of Alumina Nanoparticle Water-Based Suspensions in Ball-onThree-Plate Testing, Tribol. Lett. 65(2) (2017) 40.

[23] H. Wu, J. Zhao, X. Cheng, W. Xia, A. He, J.-H. Yun, S. Huang, L. Wang, H. Huang, S. Jiao, Z. Jiang, Friction and wear characteristics of TiO2 nano-additive water-based lubricant on ferritic stainless steel, Tribol. Int. 117 (2018) 24-38.

[24] H. Wu, J. Zhao, W. Xia, X. Cheng, A. He, J.H. Yun, L. Wang, H. Huang, S. Jiao, L. Huang, S. Zhang, Z. Jiang, A study of the tribological behaviour of $\mathrm{TiO}_{2}$ nano-additive water-based lubricants, Tribol. Int. 109 (2017) 398-408.

[25] Y. Gu, X. Zhao, Y. Liu, Y. Lv, Preparation and tribological properties of dual-coated TiO 2 nanoparticles as water-based lubricant additives, J. Nanomater. 2014 (2014) 2.

[26] Y. Bao, J. Sun, L. Kong, Effects of nano-SiO2 as water-based lubricant additive on surface qualities of strips after hot rolling, Tribol. Int. 114 (2017) 257-263.

[27] Y.Y. Bao, J.L. Sun, L.H. Kong, Tribological properties and lubricating mechanism of SiO 2 nanoparticles in water-based fluid, IOP Conference Series: Materials Science and Engineering 182(1) (2017) 012025.

[28] C. Wu, S.X. Hou, H.Q. Zhang, X.M. Jia, Study and Evaluation on Dispersion of Molybdenum Disulfide in Aqueous Solution, Adv. Mater. Res., Trans Tech Publ, 2013, pp. 2175-2178.

[29] B.M. Zhang, J.L. Sun, Tribological performances of multilayer-MoS 2 nanoparticles in water-based lubricating fluid, IOP Conference Series: Materials Science and Engineering 182(1) (2017) 012023.

[30] Q.-j. MENG, S.-m. ZHANG, L.-g. YU, Z.-s. WU, Z.-j. ZHANG, Preparation of nanoscale water-dispersible molybdenum disulfide and evaluation of its tribological behavior [J], Tribology 31(2) (2011) 144-149.

[31] C. Zhang, S. Zhang, L. Yu, Z. Zhang, Z. Wu, P. Zhang, Preparation and tribological properties of watersoluble copper/silica nanocomposite as a water-based lubricant additive, Appl. Surf. Sci. 259 (2012) 824830.

[32] M. Sadeghalvaad, S. Sabbaghi, Application of TiO2/Polyacrylamide Core-Shell Nanocomposite as an Additive for Controlling Rheological and Filtration Properties of Water-Based Drilling Fluid, J. Nanofluids 6(2) (2017) 205-212.

[33] G. Jiang, W. Guan, Q. Zheng, A study on fullerene-acrylamide copolymer nanoball-a new type of water-based lubrication additive, Wear 258(11-12) (2005) 1625-1629.

[34] H. Lei, W. Guan, J. Luo, Tribological behavior of fullerene-styrene sulfonic acid copolymer as waterbased lubricant additive, Wear 252(3-4) (2002) 345-350.

[35] Y. Peng, Y. Hu, H. Wang, Tribological behaviors of surfactant-functionalized carbon nanotubes as lubricant additive in water, Tribol. Lett. 25(3) (2007) 247-253. 
[36] O. Elomaa, V.K. Singh, A. Iyer, T.J. Hakala, J. Koskinen, Graphene oxide in water lubrication on diamond-like carbon vs. stainless steel high-load contacts, Diamond Relat. Mater. 52 (2015) 43-48.

[37] H. Kinoshita, Y. Nishina, A.A. Alias, M. Fujii, Tribological properties of monolayer graphene oxide sheets as water-based lubricant additives, Carbon 66 (2014) 720-723.

[38] S. Liang, Z. Shen, M. Yi, L. Liu, X. Zhang, S. Ma, In-situ exfoliated graphene for high-performance waterbased lubricants, Carbon 96 (2016) 1181-1190.

[39] Y. Liu, X. Wang, G. Pan, J. Luo, A comparative study between graphene oxide and diamond nanoparticles as water-based lubricating additives, Sci. China Technol. Sci. 56(1) (2013) 152-157.

[40] H.-J. Song, N. Li, Frictional behavior of oxide graphene nanosheets as water-base lubricant additive, Appl. Phys. A 105(4) (2011) 827-832.

[41] X. Ye, L. Ma, Z. Yang, J. Wang, H. Wang, S. Yang, Covalent functionalization of fluorinated graphene and subsequent application as water-based lubricant additive, ACS Appl. Mater. Interfaces 8(11) (2016) 7483-7488.

[42] A. He, S. Huang, J.-H. Yun, Z. Jiang, J. Stokes, S. Jiao, L. Wang, H. Huang, The pH-dependent structural and tribological behaviour of aqueous graphene oxide suspensions, Tribol. Int. 116 (2017) 460-469.

[43] A. He, S. Huang, J.-H. Yun, Z. Jiang, J.R. Stokes, S. Jiao, L. Wang, H. Huang, Tribological Characteristics of Aqueous Graphene Oxide, Graphitic Carbon Nitride, and Their Mixed Suspensions, Tribol. Lett. 66(1) (2018) 42.

[44] L. Chang, Z. Zhang, C. Breidt, K. Friedrich, Tribological properties of epoxy nanocomposites - I. Enhancement of the wear resistance by nano-TiO2 particles, Wear 258(1-4) (2005) 141-148.

[45] P.U. Aldana, F. Dassenoy, B. Vacher, T. Le Mogne, B. Thiebaut, WS2 nanoparticles anti-wear and friction reducing properties on rough surfaces in the presence of ZDDP additive, Tribol. Int. 102 (2016) 213-221.

[46] L. Rapoport, V. Leshchinsky, I. Lapsker, Y. Volovik, O. Nepomnyashchy, M. Lvovsky, R. Popovitz-Biro, Y. Feldman, R. Tenne, Tribological properties of WS 2 nanoparticles under mixed lubrication, Wear 255(7) (2003) 785-793.

[47] D.X. Peng, Y. Kang, R.M. Hwang, S.S. Shyr, Y.P. Chang, Tribological properties of diamond and SiO2 nanoparticles added in paraffin, Tribol. Int. 42(6) (2009) 911-917.

[48] X. Tao, Z. Jiazheng, X. Kang, The ball-bearing effect of diamond nanoparticles as an oil additive, J. Phys. D: Appl. Phys. 29(11) (1996) 2932.

[49] D. Jiao, S.H. Zheng, Y.Z. Wang, R.F. Guan, B.Q. Cao, The tribology properties of alumina/silica composite nanoparticles as lubricant additives, Appl. Surf. Sci. 257(13) (2011) 5720-5725.

[50] Y.L. Gu, F. Jerome, Glycerol as a sustainable solvent for green chemistry, Green Chem. 12(7) (2010) 1127-1138.

[51] Y. Su, L. Gong, D. Chen, An investigation on tribological properties and lubrication mechanism of graphite nanoparticles as vegetable based oil additive, J. Nanomater. 16(1) (2015) 203.

[52] Q. Xue, W. Liu, Z. Zhang, Friction and wear properties of a surface-modified TiO2 nanoparticle as an additive in liquid paraffin, Wear 213(1-2) (1997) 29-32.

[53] A. Begelinger, A. De Gee, On the mechanism of lubricant film failure in sliding concentrated steel contacts, Journal of Lubrication Technology 98(4) (1976) 575-579.

[54] K.C. Ludema, A review of scuffing and running-in of lubricated surfaces, with asperities and oxides in perspective, Wear 100(1-3) (1984) 315-331.

[55] J. Lee, S. Cho, Y. Hwang, H.J. Cho, C. Lee, Y.M. Choi, B.C. Ku, H. Lee, B. Lee, D. Kim, S.H. Kim, Application of fullerene-added nano-oil for lubrication enhancement in friction surfaces, Tribol. Int. 42(3) (2009) 440447. 